University of Rhode Island

DigitalCommons@URI

Open Access Master's Theses

1984

\title{
A Comparison of Extinction and Reinforcement-Based Response Elimination Technique
}

Stuart Vyse

University of Rhode Island

Follow this and additional works at: https://digitalcommons.uri.edu/theses

\section{Recommended Citation}

Vyse, Stuart, "A Comparison of Extinction and Reinforcement-Based Response Elimination Technique" (1984). Open Access Master's Theses. Paper 1568.

https://digitalcommons.uri.edu/theses/1568

This Thesis is brought to you for free and open access by DigitalCommons@URI. It has been accepted for inclusion in Open Access Master's Theses by an authorized administrator of DigitalCommons@URI. For more information, please contact digitalcommons-group@uri.edu. 
A COHPARISON OF EXTINCTION AND REINFORCEMENT-BASED BESPONSE ELIMINATION TECHNIQUES

BI

STUART YYSE

A THESIS SUBHITED IN PARTIAL FOLFILLAENT OF THE BEQUIREMENTS FOR THE DEGREE OF MASTER OF ARTS

IN

PS YCHOLOGY

JNIYERSITY OF BHODE ISLAND 1984 
Abstract

over a period of eight daily sessions, 40 male rats acquired an operant lever response under an FI 10-sec schedule of reinforcement. Following this training the subjects vere randomly assigned to one of four treatment conditions designed to eliminate this response: 1) extinction (BXT), 2) differential reinforcement of other behavior (DRO), 3) reinforcement of an alternate response (ALT-R1) , or 4) reinforcement of an alternate response pluㅗㅡ a response-reinforcement delay for the original response (ALT-R10). These four response elimination contingencies were compared under three experimental conditions: 1) a five session treatment phase in which each response elimination procedure was in effect, 2) a five session extinction phase in which no reinforcement was available for any of the four groups, and 3) a single reacguisition session in which reinforcement was reinstated for the original response. The results of the treatment phase showed the ALT-R10 procedure to be significantly more effective in eliminating the original response than either EXT or ALT-B1, and in the final session of this phase, ALT-R10 was also more effective than DRO. In the extinction 
phase, subjects in all three of the reinforcement-based response elimination procedures showed a rebound in original responses resulting in a significantly higher rate of responding than for subjects in the EXT group, and ALT-R1 subjects showed significantly more original responses than either DRO or ALT-R10 subjects. Finally, ALT-R10 showed significantly ferer original responses than DRO in the first session of the extinction phase but was not significantly different from this group in the other four sessions of this phase. In the reacquisition session, the EXT group was significantly slower to recover the original response than all of the reinforcement-based treatment groups, and DRO showed significantly slower reacquisition than ALT-R 1 or ALT-B10. Finally, ALT-R 1 and ALT-R10 were essentially equivalent in reacquisition. The theoretical relevance of these effects for reinforcement-based response elimination procedures is discussed, as vell as the implications of this research for the applied use of similar contingencies aimed at the treatment of human behavioral excesses. 
Acknowledgements

This section of a graduate thesis is something of a formality, and perhaps the most traditional aspect of this formality is the acknowledgement of the assistance of the thesis committee. However in this case my remarks are not stimulated by custon. This project, whose conception and development have spanned more than a year, represents the major product of my early graduate training in psychology, but the contributions of my committee have not been limited to this research. Each of them, Jerry Cohen. James Ioy, James A. Mulick, and lark D. Bapport, has served as a mentor and colleague and has listened patiently to sad stories and improbable schemes. Special thanks go to my major professor, Nelson Smith, who has always provided me with the guidance, support, and materials to make my graduate education as comprehensive as I had the energy to make it.

I would also like to thank Jack wichael of Western Michigan University for his helpful advice. This work has been greatly improved by conversations with him and readings suggested by him.

This project could not have been completed uithout the indefagitable assistance of my lab mates, Sara cottrill. 
Thomas Fagan, Carol Wentworth, and Beth thaley, who ran innumerable subjects, often under difficult circumstances.

Tro graduate student colleagues deserve praise. Stephen A. Neill has been a good friend and, as m 7 direct predecessor in the lab, a valuable teacher. Joseph Rossi has given useful advice on statistical issues. Finally, my vife, Judith, has suffered much immediate discomfort in the name of distant and rather vague revards. Her support has been an essential part of my most important accomplishments. 
Preface

As behavioral psychology enters its seventh decade it appears to have passed into an adolescence marked both by expansion into new and diverse areas of research (Epling $\varepsilon$ Pierce, 1983) and a drifting apart of applied and basic behavioral research (Deitz, 1978; Michael, 1980). While the former is considered by most to be good nevs, many researchers have expressed serious concern about the latter. One of the major controversies surrounding this basic-applied schism has been the increased frequency ithin applied behavior analysis of studies employing package independent variables. such as "overcorrection". "response cost", and "feedback". These interventions combine a number of elements wose relation to more clearly defined experimental principles (e.g. punishment, negative reinforcement, and stimulus control) is unclear. As Deitz (1978) suggests, this development vithin applied research reflects a greater concern for effects upon dependent variables than for the discovery of functional relationships between independent and dependent variables.

Perhaps another aspect of this divergence of basic and applied research is the increased specialization of issues examined in current basic research journals. The advent of 
research on the matching law (Herrnstein, 1961) and various forms of phylogenic behavior has helped to drive a wedge between the two spheres by making basic research less accessible to applied professionals. Research in these areas is often concerned with theoretical issues of dubious applied significance.

Set against this background, the present graduate thesis is something of an anachronism. It is basic animal research wich, while having considerable theoretical significance, is primarily an analog study directed at an applied question. The response elimination issues examined in this study are more consistent with the topics addressed in applied journals, yet this characteristic may be one of its strengths.

The growth of applied behavior analysis in the 1950's and $60^{\prime} \mathrm{s}$ was a direct result of earlier animal research; however, in the intervening years applied research has become an independent discipline with its oun unique history and methods. While the practical benefits of this applied technology have been many. the society which reinforces these advances is in part responsible for the theoretical imprecision cited by uichael (1980) and Deitz (1978). The solutions to these problems will come primarily with changes in the language, methods, and topics of applied research, but the present study represents another type of solution. By returning applied issues to the laboratory, research of 
this type may provide both improved experimental control and the kind of functional analysis Michael (1980) and Deitz (1978) adrocate. I hope the following pages argue convincingly for the return of applied researchers to the animal laboratory and stand as an example of effective communication between the two worlds of behavior analysis. 


\section{Table of contents}

Abstract

ii

Acknouledgements

iv

Preface

Introduction

Uethod

vi

Subjects

Apparatus

Procedure

12

12

Results

St at istical Analyses

Original Lever Analyses 18

Phase I 18

Phase II $\quad 23$

Phase III $\quad 29$

Phase IV $\quad 35$

Savings Analysis $\quad 41$

Alternate Lever analyses 43

Phase I $\quad 43$

Phase II $\quad 46$

Phase III $\quad 52$

Phase IV $\quad 58$

Reinforcement Rate Analyses 65

Phase I $\quad 65$

$\begin{array}{ll}\text { Phase II } & 67\end{array}$

Phase IV $\quad 74$

Response Pattern Analyses 80

Discussion $\quad 94$

A Few Tords about Terminology 100

Alternate Reinforcement and the vatching Lau 102

Some Applied Implications of this Research 103

Limits to the Applied Implications of this Research 105

Conclusions $\quad 110$

appendices 
Table 1. Means and Standard Deviations of original Lever Responses in Phase I.

Table 2. Means and Standard Deviations of original Lever Responses in Phase II.

Table 3. Means and Standard Deviations of Log Transformed original Lever Responses in Phase II.

Table 4. Means and Standard Deviations of Original

Lever Responses in Phase III.

Table 5. Heans and Standard Deviations of Log Transformed original Lever Responses in Phase III.

Table 6. Means and Standard Deviations of Original Lever Responses in Phase IV.

Table 7. Means and Standard Deviations of Log

Transformed original Lever Responses in Phase IV.

Table 8. Means and Standard Deviations of Total

original Lever Responses Across phases II and III.

Table 9. Means and Standard Deviations of Alternate Lever Responses for Phase I.

Table 10. Means and Standard Deviations of Log

Transformed Alternate Lever Responses for Phase I.

Table 11. Means and Standard Deviations of Alternate Lever Responses for Phase II.

Table 12. Means and Standard Deviations of Log

Transformed Alternate Lever Responses in Phase II.

Table 13. Means and Standard Deviations of Alternate Lever Responses in Phase III.

Table 14. Means and Standard Deviations of Log

Transformed Alternate Lever Responses for Phase III.

Table 15. Means and Standard Deviations of alternate Lever Responses in Phase IV. 
Table 16. Means and Standard Deviations of Log

Transformed Alternate Lever Responses in Phase IV.

Table 17. Means and Standard Deviations of Total

Reinforcements for Phase I.

Table 18. Means and Standard Deviations of Total Reinforcements for Phase II.

Table 19. Means and Standard Deviations of Arcsin Transformed Total Reinforcements for Phase II.

Table 20. Means and Standard Deviations of Total Reinforcements for Phase IV.

Table 21. Means and Standard Deviations of Arcsin Transformed Total Reinforcements for Phase IV. 


\section{List of Figures}

Figure 1. Mean original lever responses for each group for phase $I$.

Figure 2. Mean log transformed oriqinal lever responses for each group for phase II.

Figure 3. Hean log transformed original lever responses for each group for phase III.

Figure 4. bean log transformed original lever responses for each group for phase IV.

Figure 5. Mean log transformed alternate lever responses for each group for phase II.

Figure 6. Mean log transformed alternate lever responses for each group for phase III.

Figure 7. Mean log transformed alternate lever responses for each group for phase IV.

Figure 8. Wean arcsin transformed total reinforcements for each group for phase II.

Figure 9. Hean arcsin transformed reinforcements per minute for each group for phase IV.

Figure 10. Representative cumulative records of subjects in phases $I$ and II.

Figure 11. Representative cumulative records of subjects in phase II.

Figure 12. Representative cumulative records of subjects in phase III.

Figure 13. Representative cumulative records of subjects in phase Ir. 


\section{Introduction}

The search for effective treatments for behavioral excesses in applied psychology has led to the successful use of several punishment techniques (Lovaas \& Simmons, 1969; Plosgrove $\&$ Reith, 1983; Rapport, Uurphy, $\varepsilon$ Bailey, 1982) as well as reinforcement procedures (Deitz $\&$ Bepp. 1983) for the elimination of a response. However, current concerns about the restrictireness of aversive procedures (Barton, Brulle, $\varepsilon$ Repp, 1983; Martin, 1975) and other, undesirable effects thought to accompany the use of punishment (skinner. 1953) have given greater importance to research in $v$ arious reinforcement-based response elimination procedures. Basic research in this area has been primarily in two parallel lines, one involving the differential reinforcement of other behavior (DRO) or omission training (OT) and the second involving the reinforcement of a specific alternative response (ALT-R).

As outlined by Uhl and Garcia (1964). DRO schedules, like free operant a roidance schedules, are defined bY two temporal schedule parameters: 1) the reinforcement-reinforcement interval and 2) the response-reinforcement interval. Since the DRO contingency allows for the reinforcement of any response other than the 
one targetted for elimination, the

reinforcement-reinforcement interval dictates the rate of reinforcement provided the target response does not occur. The response-reinforcement interval determines the amount of time which must elapse after a response has been made before reinforcement is delivered.

DRO was first introduced as a control procedure for examining behavioral contrast in multiple schedules (Reynolds, 1961), but its response elimination effects soon engendered a new line of research (Johnson, McGlynn, $\mathcal{E}$ Topping. 1973; Lowry \& Lachter, 1977; Lulick, 1975; Mulick \& Leitenberg. 1978; Nevin, 1968; Pacitti \& Smith. 1977: Topping, Larmi, E Johnson, 1972; Uhl \& Garcia, 1969; and Zeiler. 1970, 1971, 1976, 1977, 1979). Most studies comparing this schedule to extinction (EXT) have shown that the DRO contingency produces more rapid response elimination (Johnson, et al, 1973; Pacitti \& Smith, 1977; Topping et a 1.. 1972; Topping $\varepsilon$ Ford, 1974) and, when reinforcement is reinstated for the target response, is more resistant to reacquisition (Pacitti $\varepsilon$ Smith, 1977; Topping et al.. 1972). However most studies which follow the DRo treatment phase with a period of extinction during which no reinforcement is available have shown a characteristic rebound in the target response (Mulick, 1975; Mulick $\varepsilon$ Leitenberg. 1978; Pacitti \& Smith, 1977) . This effect, which is characteristic of punishment and 
reinforcement-based response elimination techniques, has been labelled "compensatory recovery" (Boe $\varepsilon$ Church, 1967). Ohl and Garcia (1969, Experiment 1) found that oT produced slover response elimination in rats than EXT: however, in a second experiment thl and Garcia provided a brief blackout after reinforcement delivery which reversed the effectiveness of the two treatments. This result suggested that a "chaining" effect had occurred in the first study in which the delivery of reinforcement was so strongly associated with the response that early in OT the presence of food actually increased the probablity of the response. Hulick and Leitenberg (1978) reported a similar chaining pattern in the responses of OT subjects.

Two multiple schedule experiments (Lowry $\varepsilon$ Lachter, 1977: Mulick, Leitenberg, $\varepsilon$ Rawson, 1976) in which single subjects were alternately exposed to several response elimination treatments per session, showed results wich were in contrast to most between groups studies. In both cases ALT-B produced the most rapid response elimination vile DRO and EXT showed more moderate and essentially equivalent decrements in response rate. However, the most remarkable aspect of these studies is that neither showed a rebound effect for either DRO or ALT-R during the extinction phase. These consistent results seem to indicate that the multiple schedule design is a unique case which produces different effects than between groups studies. For the 
purpose of extrapolation to likely human applications of these procedures, the between groups case is more informative since rapid alternation of treatments is rare in clinical settings.

Zeiler's recent research with DRO has been involved with parametric analyses of the response-reinforcement intervals (1977) and the study of conjoint schedules in which DRO and either a fixed time schedule of food delivery (FT) or a fixed ratio schedule of reinforcement (FR) are simultaneously in effect (1977, 1979). These studies have greatly increased our understanding of the DRO contingencyThe conjoint schedule studies (Zeiler, 1977, 1979) are of particular note because they more accurately simulate the applied case in which DRO is used as a treatment for the elimination of a response which, nevertheless, is still receiving reinforcement on some intermittent schedule. Hovever, unlike the studies cited earlier, these experiments were limited to DRO and did not compare it to other response elimination techniques.

Other than DRO or OT the most frequently studied reinforcement technigue for elimination of a response is alternate response (ALT-R), which normally involves the introduction of a second manipulandum in the chamber upon which responses are made contingent during the response elimination phase. Many studies have found this to be a treatment which produces more rapid elimination of the 
original response than EXT (Boe, 1964; Enkema, Slavin, Spaeth, \& Nueringer, 1972; Leitenberg, Bawson, E Bath, 1970: Leitenberg, Rauson, E Hulick, 1975; Lowry $\&$ Lachter, 1977: Uulick, 1975: Uulick \& Leitenberg, 1978; Pacitti $\varepsilon$ Smith, 1974: Rawson $\&$ Leitenberg, 1973): hovever, in studies which followed ALT-R treatment with a period of no reinforcement for either response (EXT), all but the within subject studies (Lowry \& Lachter, 1977; Uulick, Leitenberg. E Rawson, 1976) showed a rebound of responding similar to that found in the DRO studies. Indeed, a number of group studies (Leitenberg et al.. 1970; Pacitti \& Smith, 1977) have shown that when total responses in both the treatment and extinction phases are compared for both EXT and ALT-R groups no significant savings was found for $A L T-R$. Recently. Epstein and his associates (Epstein, in press; Epstein \& Medalie, 1983) have related this phenomenon, which is similar to the "compensatory recovery" of DRO (Boe $\varepsilon$ Church, 1967), to a principle they call "resurgence". This principle states that, "when, in a given situation, recently reinforced behavior is no longer reinforced, behaviors that were previously reinforced tend to recur" (Epstein, in press). Epstein has suggested that resurgence plays an important part in a number of problems solving activities.

The rebound effect is of theoretical importance because it is related to an early theory of punishment proposed by Estes (1944) which suggested that the punishment of a 
learned response only suppresses it temporarily and that complete elimination can only come after the response has undergone the normal process of extinction. More recently this theory has been criticized on several points (see Azrin \& Holz, 1966) and experimental evidence suggests that the punishment of responses with powerful electric shock can produce more permanent effects. Nevertheless, the work in ALT-R and DRO are relevant to this issue since the great majority of studies have found no significant difference in the number of responses made by AIT-K, DRO, or EXT groups when both treatment and extinction phases are combined. These results, like Estes (1944) early work in punishment, might lead to the conclusion that reinforcement-based response elimination techniques only produce a temporary suppression effect; however, Leitenberg et al. (1975) have shown that when the ALT-R treatment phase was extended for 27 days, switching to extinction did not produce a rebound in responding and a significant savings in total responses was found over the EXT group. Thus, while there is some evidence that reinforcement-based procedures can produce relatively rapid and permanent suppression, few contingencies have been found wich were successful in this end.

The present study was designed to explore the elimination of a previously learned response using a contingency of reinforcement which combined some aspects of 
both ALT-R and DRO. Simply stated the contingency consisted of an ALT-R procedure which included a substantial response-reinforcement interval for the original response, similar to DRO. This arrangement made reinforcement available on a fixed interval schedule for an alternate response and set up a brief interruption of this schedule each time an original response was made. It was hoped that this addition of a penalty for original responses would prevent the usual rebound during extinction and produce more durable effects in reacquistion.

This aspect of the study is related to an important issue wich has never been fully addressed in the alternate response literature. Since by definition the ALT-R procedure involves two manipulanda, different at least in location in the chamber, it qualifies as a special case of concurrent operant in which one manipulandum is associated with a schedule of reinforcement and the other is associated with extinction (Catania, 1966). However, as Catania (1966) has outlined in detail, a critical problem in the study of concurrent operants is the independence of the responses and the schedules of reinforcement associated with them. If the two operants are not made sufficiently independent, the close temporal relationship of reinforcement as a result of a schedule on one manipulandum and responses made on another may support superstitious responses on one or both manipulanda or a pattern of switching from one to the other. 
Normally, schedules of reinforcement are made independent by programming a changeover delay (COD) (Catania, 1966) which prevents the reinforcement of a response for a brief period of time after a change from one manipulandum to another. However, this kind of independence can also be created by the physical arrangement of the manipulanda, as was the case in the present study. If the levers or keys are far enough apart, a tacit COD will be created by the time involved in moving from one to the other.

The question of independence is an important one for the alternate response literature since the length of CoDs employed have ranged from none at all (Pacitti \& Smith. 1977) to a very substantial 5 sec COD (Leitenberg et al.. 1975). Similarly, the physical arrangement of the manipulanda has varied in different studies. Yet neither the physical or temporal independence of schedules or responses has been systematically examined in the alternate response literature.

The ALT-R procedure as studied in the animal literature is related to two applied response elimination procedures. The most common of these is differential reinforcement of incompatible behavior (DRI) (Deitz E Repp, 1983; Mulick, Schroeder, $\varepsilon$ Rojahn, 1980; Tarpley $\&$ Schroeder, 1979; Woods, 1983). As defined by Woods (1983), DRI is "a procedure in which the contingent application of a stimulus event strengthens a response which is incompatible 
(physically or practically) with another, undesired response" ( $p$. 60). For two of the subjects studied by Tarpley and Schroeder (1979), self-injurious hand-to-head hitting was reduced by reinforcing ball-trading. This was a typical and very successful application involving a physically incompatible response, except that in this case the investigators required that ball-trading occur uninterrupted for a fixed interval in order to obtain reinforcement.

Deitz and Repp (1983) have identified another applied response elimination procedure which is related to the ALT-R contingency of the experimental literature. Differential reinforcement of alternate behavior (DRA) is defined as reinforcement of a response which is not "physically or practically" incompatible with the behavior targeted for elimination. While less frequently studied, DRA procedures have also been effective in a number of cases (Deitz $\&$ Repp. 1983).

In the present study, four different response elimination procedures vere compared: 1) EXT, 2) DRO, 3) ALT-R, and 4) ALT-R plus a $10 \mathrm{sec}$ response-reinforcement interval. In this case the ALT-R vas analogous to an applied DRI procedure since the manipulanda in this study were physically separated and a short COD was employed. The $13.1 \mathrm{~cm}$ distance between the levers did not make simultaneous responses physically impossible, given the 
typical length of a $250 \mathrm{~g}$ Sprague-Davley rat, yet such responses were extremely unlikely•

The group of primary interest was the ALT-R group in which a response on the original lever created a $10 \mathrm{sec}$ delay in the availablity of reinforcement on the alternate lever. In both its experimental and applied senses this contingency combined aspects of the ALT-R (OI DRI) and DRO procedures. Reinforcement was available only for a specified response (as in AIT-R and DRI): hovever, the occurrence of an original response produced a $10 \mathrm{sec}$ delay in the availablity of reinforcement for the alternative response (similar to DKO). It vas hoped that, like the DRO contingency, this procedure would provide a mild punishment for responses on the original lever. This penalty combined with reinforcement for a specific alternative response might result in more efficient suppression than DRO or ALT-R alone and produce the durable effect which has been observed in studies involving DRO.

In all four groups of the present study the original training was on an FI 10-sec schedule for five days, and in the three reinforcement-based treatment procedures the optimal reinforcement-reinforcement intervals were also matched at $10 \mathrm{sec}$ This arrangement equated the three groups on the potential rate of reinforcement, both during training and treatment phases.

The sequence of treatment phases included training, 
response elimination treatment, extinction, and reacquisition. The extinction and reacquisition phases are included as tests of the durablity of the various response elimination techniques, since during the applied use of any of these procedures it is reasonable to assume that behavior modification programs will experience brief interruptions or that on occasion inappropriate behaviors will be inadvertantly reinforced. In light of this, it is important to find contingencies which produce durable suppression under conditions of extinction and reacquisition.

The present study has one primary hypothesis: the length of changeover delay of an ALT-R contingency contributes to its response elimination effects. Specifically, it is predicted an ALT-R contingency with a 10-sec changeover delay penalty will control lower rates of responding than an ALT-B contigency without a substantial penalty. This prediction is expected to hold both while the two contingencies are in effect, as well as after both have been switched to extinction. Finally, it is predicted that an ALT-R plus penalty condition will control lower rates of responding during a brief reacquisition phase. No prediction is possible regarding the relative effectiveness of either of these contingencies in comparison to DBO. 
Method

\section{suujiect $\underline{s}$}

The subjects were 40 male Sprague-Dawley rats. Each weighed between 250 and $350 \mathrm{~g}$ prior to food deprivation and was individually housed and provided with free access to water throughout the course of the study. For three days prior to shaping, each subject was deprived of all food, and following shaping was maintained at approximately $80 \%$ of his free feeding weight throughout all phases of the experiment.

\section{Apparatuuㅗ}

Two Coulbourn Instruments model \# E10-10 operant chambers were employed. The front and back walls were aluminium and were $25 \mathrm{~cm}$ wide. The side valls were clear Plexiglas and were $30 \mathrm{~cm}$ wide. The chambers were $29 \mathrm{~cm}$ tall and each was contained in a sound attenuating housing. The front wall of each chamber was equipped with two operant levers and a food cup. The levers extended $2.0 \mathrm{~cm}$ into the chamber $2.8 \mathrm{~cm}$ above the grid floor and were $3.0 \mathrm{~cm}$ wide. The levers were spaced $13.1 \mathrm{~cm}$ apart, and the food cup was recessed in the wall of the chamber and centered between the two levers $1.8 \mathrm{~cm}$ above the grid floor. Masking noise was provided by ventilating fans attached to each housing, and programming was accomplished using standard electro-mechanical equipment which was kept in an adjoining 
room. Noyes precision pellets were used as reinforcement.

\section{Procedure}

Prior to initial shaping each subject was handled on at least two different days and was acclimated to the experimental chamber. Immediately after his daily session each subject vas returned to the animal colony and, a few hours later, was given enough rat chow to maintain him at $80 \%$ of his pre-deprivation weight.

other than on the first shaping day, all sessions were conducted five days a week (Monday through Friday) at approximately the same time each day and lasted 15 min. on the first day of shaping, the session was conducted with the door of the housing open in order to make the subject clearly visible, but during all other sessions the housing was closed.

Shaping. The first day of shaping for each subject was conducted on a sunday. Each subject was randomly assigned to one of the two chambers and to a left-hand or right-hand lever for original response training. Initially, hand shaping was terminated when the subject made 40 reinforced lever presses, and if this criterion was not met within 75 min the animal was replaced by another. However, early in the experiment, due to a number of failures to produce 40 lever presses within the 75 min time limit, the shaping procedures were changed. All animals were deprived of food 
for four days prior to shaping, and the criterion was reduced to 30 responses within the 75 min session.

Pretraining. On the second and third days of the experiment, the subject was placed in the chamber and an FI 10-sec schedule of reinforcement was programmed on the original lever. In order to firmly establish the response, the session length on these two days was $30 \mathrm{~min}$.

phase I--Traiㅡㅁㅛ. Following the first three sessions, the daily session length was reduced to $15 \mathrm{~min}$ and each subject received five days of FI 10-sec training on the original response. A criterion for response rate during Phase I was set such that any subject who did not produce an mean of 100 responses per day across the five days of this condition was eliminated and replaced. Following this preliminary training, subjects were randomly assigned to one of the four treatment groups. Each group consisted of 10 subjects.

Phase II--Treatment. This phase of the experiment lasted five days during which each subject was exposed to one of the following treatment conditions.

Extinction(EXT). Beginning on the first day of treatment each subject in this group received no reinforcement for any response.

Differential Reinforcement of other Behavior (DRO). This group was programmed for a DRO contingency with matched $10 \mathrm{sec}$ reinforcement-reinforcement and $10 \mathrm{sec}$ 
response-reinforcement intervals for responses on the original lever. Under this arrangement each subject received reinforcement every $10 \mathrm{sec}$ as long as the original response did not occur; however, each original response which was made set up a 10 sec delay in reinforcement. Alteeㅁaㅡㄹ Response $(A L T-R 1)$. Under this treatment condition reinforcement was made available on the alternate lever on the same FI-10 sec schedule as was programmed on the original lever during the previous phase, and responses on the original lever were not reinforced. A 1 sec COD was programmed for responses on the original lever in order to prevent the chaining of responses or the adventitious reinforcement of switching from one lever to the other. Alternate Response_plus_10 sec_penalty (ALT-R10) This treatment condition was the same as the ALT-R group with the addition of a $10 \mathrm{sec}$ response-reinforcement interval for responses on the original lever. Under this arrangement each response on the original lever set up a $10 \mathrm{sec}$ delay in the availablity of reinforcement on the alternate lever.

Phas lasted five days, during wich all subjects received no reinforcement for any response.

Phase IV--Reacquistion. This phase of the experiment involved one 15 min session which was run on the day immediately following the last day of the extinction phase. During this session, an FI 10-sec schedule of reinforcememt 
was again programmed for responses on the original lever for all the subjects.

Results

Subject Attrition

During the course of the experiment one subject died, one was eliminated for not acquiring an average of 100 responses per day across the original training phase, and 18 subjects vere eliminated for not attaining the shaping criterion in 75 min. Each of these was replaced by another animal.

Presentation of Results

The results are presented in two major sections. The first is a traditional statistical analysis of the three dependent variables coriginal lever responses, alternate lever responses, and reinforcement rate) which examines total frequencies of these measures accross sessions or minutes. The second section consists of examples of cumulative records of moment-to-moment response patterns uihin sessions.

\section{Statistical Analyses}

The following section reports the results of 12 analyses of variance peformed on various dependent 
variables. In each case a Hartley's Fmax or a Cochran's test of homogeneity of variance vas performed on the data prior to further analysis. In each case in which significant heterogeneity of variance was found $(p<.01)$ the data were transformed to minimize this problem. In four cases heterogeneity persisted after transformation. The largest $\underline{\text { max }}$ obtained on transformed data was 94.25 ( $\underline{\text { d }} \underline{f}=$ 20. 9). relative to a critical value of 15.3 (d $\underline{\underline{f}}=10,9$ ), and in one case a cochran's $c$ of .070 was obtained, relative to a critical value of .059 ( $\underline{\underline{f}}=60,9)$. Given the relatively moderate levels of heterogeneity and evidence that the analysis of variance is robust to violations of this assumption (Boneau, 1960; Glass. Peckham, E Saunders, 1972: Ramsey, 1980), ANOVA's were undertaken on the transformed data in each case.

In every instance where simple effects tests were performed, the Satterthwaite method (Winer, 1971) was used to estimate the degrees of freedom for the denominator.

In every case but one, the analyses of variance reported here are two factor designs involving one between subjects factor consisting of the response elimination treatment conditions and one within subjects factor consisting of the various levels of sessions or time. Since subjects are considered an additional randomized factor nested within the between subjects factor (Cohen, 1981: Winer, 1971), these constitute mixed design multifactor 
analyses. In each case the within subjects factor had either 5 or 15 levels, and the between subjects factor had either 3 or 4 levels. In one case, data was sumed across several levels of the within subjects factor in order to create a simple one way between groups design.

\section{original Le ver Analyses}

\section{Phase I--Training}

Table 1 shows the means and standard deviations of original responses for each treatment group across the five days of the training phase, and Figure 1 depicts of the means for each group for this phase. In this case the Hartley's test was nonsignificant $(\underline{E} \max (20,9)=15.17$, $\mathrm{p}>$ $.01)$.

Following the Hartley's test a $4 \times 5$ mixed design ANova was performed (see summary table presented in appendix A) The analysis yielded a significant effect of sessions ( (4, $144)=38.66$. $\mathrm{p}<.0011$, no significant effect of treatments $(\underline{E}(3.36)=1.25)$, and no treatment by sessions interaction $(I(12,144)=1.39)$. Figure 1 shous a general upward trend for all groups. While the means across groups differ by as much as 110 responses in session five, the large standard deviations in Table 1 illustrates why such a difference is nonsignificant. As a result, the equivalence of original training across in phase I was established. 
The effect sizes for this design vere estimated by calculating omega squared values for each effect. For the training phase the obtained values were .002 for treatment, .423 for sessions, and .013 for treatment $x$ sessions interaction, indicating that, vhile the majority of variance in this analysis is due to error, the increase in response rate for all groups across sessions accounted for over $40 \%$ of the variance. 
Table 1

Heans and standard Deviations of Total original Lever Besponses for Each Group hcross the

Five Sessions of the oriqinal Training phase

\begin{tabular}{|c|c|c|c|c|c|}
\hline \multirow[b]{2}{*}{ Group } & \multicolumn{5}{|c|}{ Sessions } \\
\hline & 1 & 2 & 3 & 4 & 5 \\
\hline \multicolumn{6}{|l|}{$\mathrm{EXT}$} \\
\hline $\begin{array}{l}\text { Hean } \\
\text { S. D. }\end{array}$ & $\begin{array}{r}221.20 \\
78.27\end{array}$ & $\begin{array}{r}219.80 \\
83.24\end{array}$ & $\begin{array}{r}227.20 \\
85.38\end{array}$ & $\begin{array}{l}261.90 \\
102.96\end{array}$ & $\begin{array}{l}296.50 \\
106.43\end{array}$ \\
\hline \multicolumn{6}{|l|}{ ALT $T$ - 1} \\
\hline $\begin{array}{l}\text { Mean } \\
\text { S.D. }\end{array}$ & $\begin{array}{r}184.00 \\
41.14\end{array}$ & $\begin{array}{r}197.10 \\
53.40\end{array}$ & $\begin{array}{r}211.60 \\
58.81\end{array}$ & $\begin{array}{r}231.00 \\
63.90\end{array}$ & $\begin{array}{r}246.60 \\
51.04\end{array}$ \\
\hline \multicolumn{6}{|l|}{ ALT-R 10} \\
\hline $\begin{array}{l}\text { Mean } \\
\text { S.D. }\end{array}$ & $\begin{array}{r}200.50 \\
62.99\end{array}$ & $\begin{array}{r}207.90 \\
61.15\end{array}$ & $\begin{array}{r}229.30 \\
80.69\end{array}$ & $\begin{array}{r}250.30 \\
58.22\end{array}$ & $\begin{array}{l}294.40 \\
100.46\end{array}$ \\
\hline \multicolumn{6}{|l|}{ DRO } \\
\hline $\begin{array}{l}\text { Hean } \\
\text { S.D. }\end{array}$ & $\begin{array}{l}221.20 \\
102.87\end{array}$ & $\begin{array}{r}246.40 \\
77.01\end{array}$ & $\begin{array}{l}287.10 \\
128.34\end{array}$ & $\begin{array}{l}317.10 \\
160.26\end{array}$ & $\begin{array}{l}356.60 \\
151.80\end{array}$ \\
\hline
\end{tabular}


Figure 1. Graph of the mean total original lever responses per session for each treatment group across the five sessions of the Training phase. 


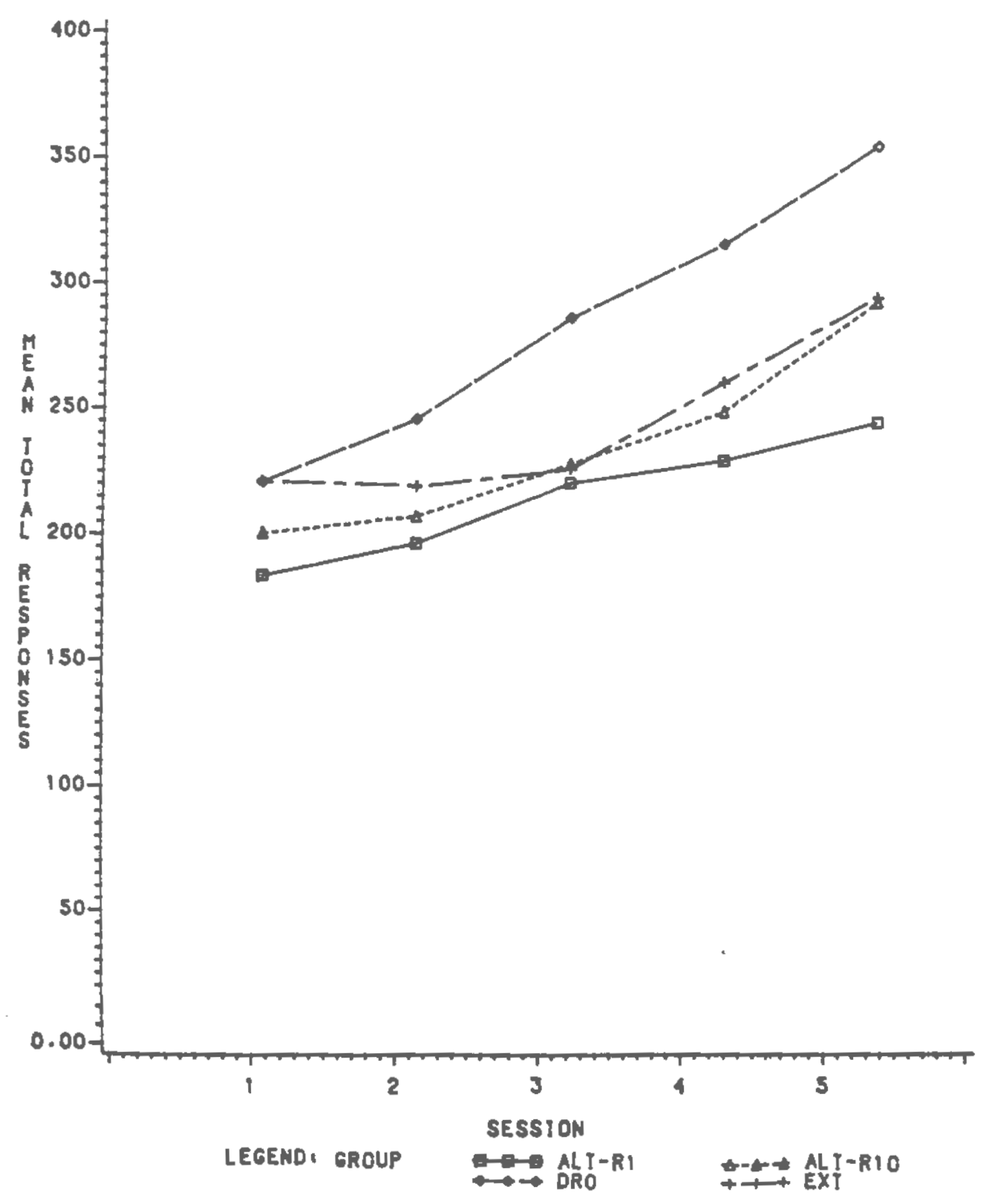




\section{Phase II--Trea tment}

Table 2 shous the means and standard deviations for total responses for each group for the five sessions of the treatment phase. In this case an Fmax test revealed significant heterogeneity of variance $(\operatorname{Fmax}(9,20)=$ 1.193.59. $\mathrm{P}<.01)$. As a result, a common $\mathrm{log}$ transformation was performed in order to equalize variances across cells (riner, 1971). The means and standard deviations of the $\log$ transformed data a re presented in Table 3. A test of homogeneity of variance on these data vas nonsignificant $(\underline{\operatorname{Fmax}}(9,20)=16.23, \mathrm{P}>.01)$ therefore the folloving analyses were performed on the transformed data.

A $4 \times 5$ mixed design anOVa was performed on the $\log$ transformed treatment phase data, and the summary table for this analysis is presented in appendix $B$. The main effect for sessions was significant at the $\mathrm{p}<.001$ level (F (4), $1441=10.98)$, and this is reflected in Figure 2, where a plot of the transformed means shovs a rapid decline across sessions for all groups. The treatments effect and sessions $x$ treatments interaction effect vere also significant at the

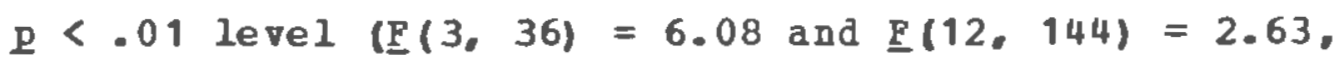
respectively).

In order to determine the relative value of each 
treatment at various points in time. simple effects tests were performed at each level of sessions. Simple effects tests for sessions 1 and 2 proved to be nonsignificant ( $\underline{F}$ ( 3 . 152) $=0.33$ and $\underline{\mathbf{F}}(3,152)=2.23$, respectively). At session 3. the simple effects test was significant ( $\underline{\text { P }}(3,152)=$ 2.80. $\mathrm{p}<.05)$, and a Newman-Kuels follow-up test found all pairwise comparisons significantly different from one another except that DRO was not different from either ALT-R1 or ALT-R10. At session 4, the simple effects test was again significant $(\underline{F}(3,152)=7.18, \underline{p}<.01)$, and the Newman-Kuels follow-up revealed all groups were significantly different except that DRO was still not different from ALT-R10. Finally, in the last session the simple effects test was again significant at the $\mathrm{p}<.01$ level $(\underline{F}(3,152)=7.05)$ and follow-up tests revealed all comparisons were significantly different except that now EXT and ALT-R1 were not different.

The Omega squared values for the treatment phase were .025 for treatments, .604 for sessions, and .033 for treatments $x$ sessions interaction. These figures suggest that the majority of the variance in this phase was due to the downward trend in log responses for all groups, and while the significant treatments and treatments $x$ sessions effects are of major interest, they combine to account for only $5.8 \%$ of the variance. 
Table 2

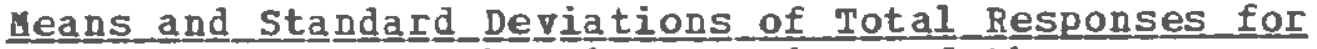
Each_Group_Across the_Five Sessions of the Trea tment Phaㅡㄹ

\section{Session}

\begin{tabular}{|c|c|c|c|c|c|}
\hline \multirow[b]{2}{*}{ Group } & & & & & \\
\hline & 1 & 2 & 3 & 4 & 5 \\
\hline \multicolumn{6}{|l|}{$\mathrm{EXT}$} \\
\hline sean & 175.40 & 76.80 & 39.20 & 29.60 & 27.60 \\
\hline S. D. & 77.14 & 33.82 & 20.77 & 16.81 & \\
\hline \multicolumn{6}{|l|}{$A L T-R 1$} \\
\hline Hean & 143.40 & 42.60 & 23.10 & 17.70 & 17.20 \\
\hline S.D. & 44.11 & 40.37 & 13.86 & 10.08 & 13.06 \\
\hline \multicolumn{6}{|l|}{$A L T-R 10$} \\
\hline Mean & 194.70 & 57.50 & 17.00 & 10.60 & 9.70 \\
\hline S. D. & 100.21 & $47 \cdot 15$ & 13.60 & 18.52 & 22.83 \\
\hline \multicolumn{6}{|l|}{ DEO } \\
\hline Hean & $247 \cdot 10$ & 100.10 & 17.80 & $12-50$ & 6.60 \\
\hline S.D. & 210.44 & 122.91 & 12.51 & 10.09 & 6.10 \\
\hline
\end{tabular}


Table 3

Means and Standard Deviations for the common

Loq Transformed Total Responses for

Each Groun Across the Five Sessions of the

Treatment phase

\begin{tabular}{|c|c|c|c|c|c|}
\hline \multirow[b]{2}{*}{ Group } & \multicolumn{5}{|c|}{ Session } \\
\hline & 1 & 2 & $\overline{3}$ & 4 & 5 \\
\hline $\mathrm{EXT}$ & & & & & \\
\hline $\begin{array}{l}\text { yean } \\
\text { S.D. }\end{array}$ & $\begin{array}{l}2.21 \\
0.20\end{array}$ & $\begin{array}{l}1.86 \\
0.18\end{array}$ & $\begin{array}{l}1.54 \\
0.27\end{array}$ & $\begin{array}{l}1.43 \\
0.23\end{array}$ & $\begin{array}{l}1.24 \\
0.48\end{array}$ \\
\hline $\begin{array}{c}A L T-R 1 \\
\text { Mean } \\
\text { S. D. }\end{array}$ & $\begin{array}{l}2.14 \\
0.13\end{array}$ & $\begin{array}{l}1.50 \\
0.38\end{array}$ & $\begin{array}{l}1.30 \\
0.31\end{array}$ & $\begin{array}{l}1.21 \\
0.26\end{array}$ & $\begin{array}{l}1.17 \\
0.29\end{array}$ \\
\hline $\begin{array}{r}A L T-R 10 \\
\text { Hean } \\
\text { S.D. }\end{array}$ & $\begin{array}{l}2.24 \\
0.21\end{array}$ & $\begin{array}{r}1.51 \\
0.62\end{array}$ & $\begin{array}{l}1.05 \\
0.54\end{array}$ & $\begin{array}{l}0.66 \\
0.62\end{array}$ & $\begin{array}{l}0.54 \\
0.59\end{array}$ \\
\hline $\begin{array}{l}\text { DRO } \\
\text { Hean } \\
\text { S. D. }\end{array}$ & $\begin{array}{l}2.29 \\
0.31\end{array}$ & $\begin{array}{l}1.80 \\
0.43\end{array}$ & $\begin{array}{l}1.19 \\
0.27\end{array}$ & $\begin{array}{l}0.92 \\
0.54\end{array}$ & $\begin{array}{l}0.76 \\
0.36\end{array}$ \\
\hline
\end{tabular}


Figu드르. Mean common log transformed total original lever responses per session for each group across the five sessions of the treatment phase. 
page 28

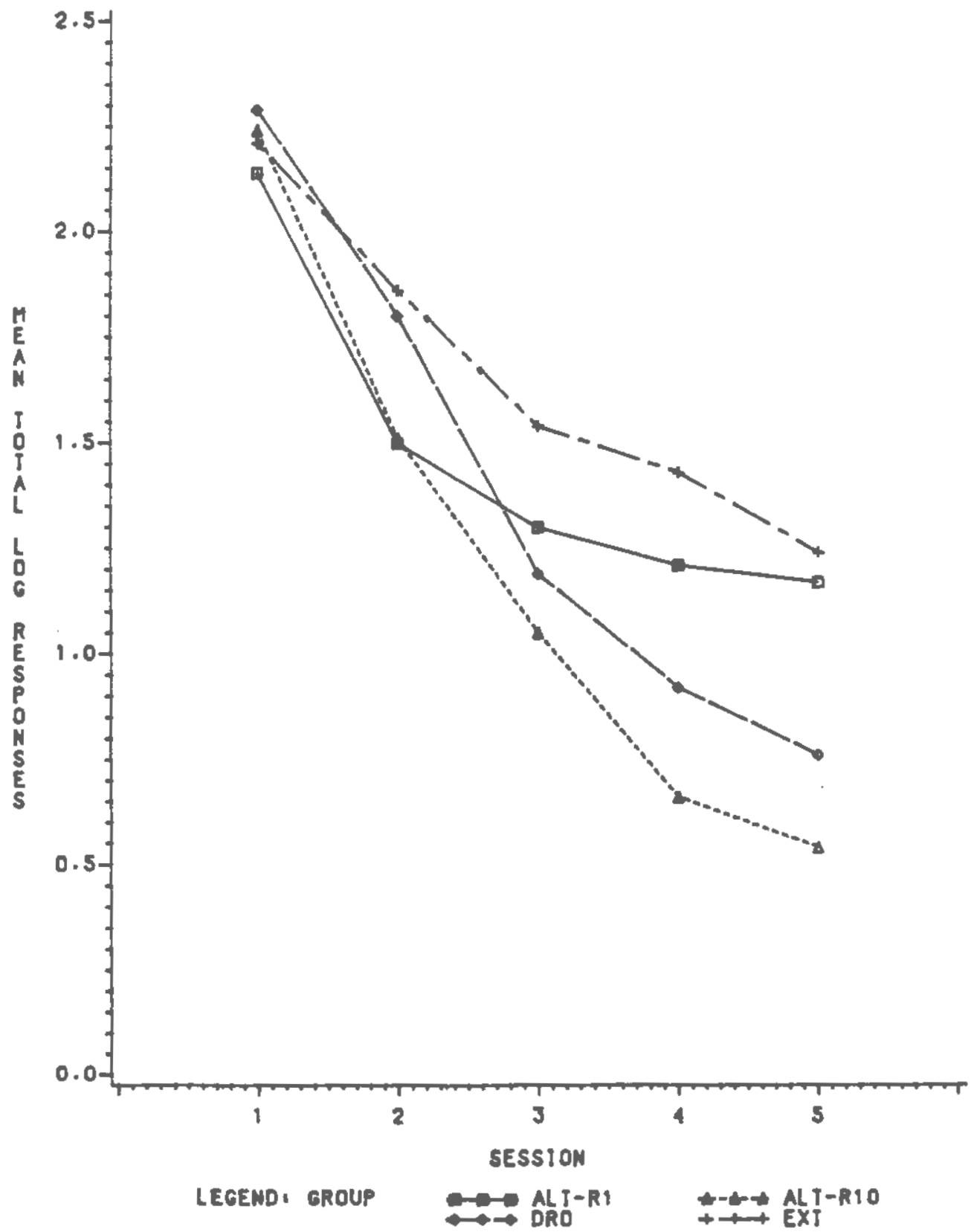




\section{Phase III--Extinction}

The means and standard deviations for total responses for each group during the five sessions of the extinction phase are presented in Table 5. A Hartley's Fmax test was performed on these data revealing significant heterogeneity of variance $(\underline{\operatorname{Fmax}}(9,20)=68.01, \underline{p}<.01)$. As a result, a common $\log$ transformation (Winer, 1971) was performed, and the resulting transformed response means and standard deviations are presented in Table 6. An Fmax test of these data proved nonsignificant $(\underline{F} \max (9,20)=15.94, \underline{p}>.01)$; as a result, the following analyses were performed on the transformed data. The $4 \times 5$ mixed design ANOVA sumary table

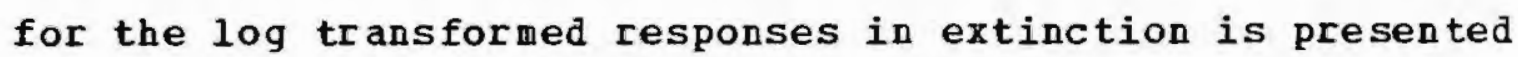
in Appendix c. Both main effects of treatments and sessions were significant at the $p<.001$ level $(\underline{F}(3,36)=17.49$ and $\underline{F}(4,144)=14.67$, respectively) and there was no significant sessions $x$ treatments interaction $(\underline{F}(12,144)=$ 0.90). This pattern is reflected in Figure 3, a graph of the means for each group across the five sessions of phase III. The plot shows a general downward trend for all groups with a consistently lower rate of total log responses for the EXT group.

Simple effects tests vere performed at all levels of sessions for the extinction phase. All five simple effects tests were significant at the $\mathrm{p}<.01$ level $(\underline{F}(3,127)=$ 13.17 at session $1 ; \underline{F}(3,127)=7.37$ at session $2 ; \underline{F}(3$, 
$127)=7.76$ at session $3: \underline{\underline{F}}(3,127)=5.53$ at session $4:$ and $\underline{F}(3,127)=9.12$ at session 5).

Newman-Kuels follow-up tests revealed a varying pattern of results across sessions. At session 1, DRO was not significantly different from $A L T-R 1$, but all other pairuise comparisons vere significant. At session 2, EXT was significantly different from all other groups (p <.01), but no other comparisons were significant. Finally, for sessions 3 through 5, DRO vs. ALT-B 10 was nonsignificant vith all other groups significantly different at $p<.05$. This pattern indicates that at all points EXT maintains a lower rate of $\log$ responses, and that for sessions 1 and 2 none of the reinforcement techniques is any more effective than any other. For sessions 3 through 5 aLT-R1 emerges as clearly less effective than the other two reinforcement-based response elimination techniques with ALT-R 10 slightly more effective than DRO, based on the results of session 1 .

The Omega squared values for this analysis were $\mathbf{~} 187$ for treatments, .207 for sessions, and .045 for the sessions $x$ treatment effect. This indicates that the treatment effect, which was of greatest experimental interest, accounts for approximately $21 \%$ of the variance in this design. 
Table 4

Means and Standard Deviations_of Total Responses_for Each Group Across the Five_Sessions_of_the

\section{Extinction Phase}

\section{Sessions}

Group

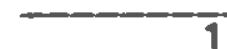

2

3

5

EXT

Mean

$\begin{array}{rrr}10.20 & 10.70 & 11.30 \\ 7.18 & 12.09 & 12.94\end{array}$

8. 20

4.20

S. D.

8. 22

4.64

ALT-R 1

Hean

67.20

46.10

38.60

37.10

25.40

S.D.

$36.59 \quad 36.06$

19.48

23. 90

17. 12

ALT-R 10

Hea $n$

44.90
31.91

$$
40.50
$$

30.90

24.90

23.00

S. D.

30.74

24. $37 \quad 20.81$

23.76

DRO

$\begin{array}{rrrrrr}\text { Gean } & 56.40 & 39.50 & 25.00 & 15.20 & 14.30 \\ \text { S.D. } & 28.60 & 22.45 & 9.30 & 8.07 & 8.82\end{array}$


Table 5

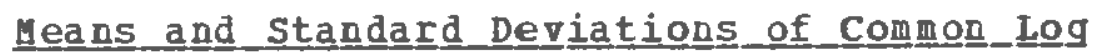

Transformed Total Responses for each Group during the rive sessions of the Extinction phase

\begin{tabular}{|c|c|c|c|c|c|}
\hline \multirow[b]{2}{*}{ Group } & \multicolumn{5}{|c|}{ Sessions } \\
\hline & 1 & 2 & 3 & 4 & 5 \\
\hline \multicolumn{6}{|l|}{ EXT } \\
\hline Hean & 0.90 & 0.94 & 0.84 & 0.88 & 0.56 \\
\hline S.D. & 0.45 & 0.31 & 0.54 & 0.25 & 0.40 \\
\hline \multicolumn{6}{|l|}{$\Delta L T-R 1$} \\
\hline Sea $\mathrm{I}$ & 1.77 & 1.57 & 1.54 & 1.50 & 1.32 \\
\hline S. D. & 0.26 & 0.23 & 0.23 & 0.28 & 0.34 \\
\hline \multicolumn{6}{|l|}{$A L T-R 10$} \\
\hline Hean & 1.56 & 1.49 & 1.36 & 1.21 & 1.15 \\
\hline S.D. & 0.34 & 0.37 & 0.40 & 0.51 & 0.48 \\
\hline \multicolumn{6}{|l|}{ DRO } \\
\hline Hean & 1.71 & 1.54 & 1.39 & 1.13 & 1.14 \\
\hline S. D. & 0.21 & 0.25 & 0.14 & 0.33 & 0.21 \\
\hline
\end{tabular}


Pigure 3. Mean common log transformed total original lever responses per session for each group across the five sessions of the extinction phase. 


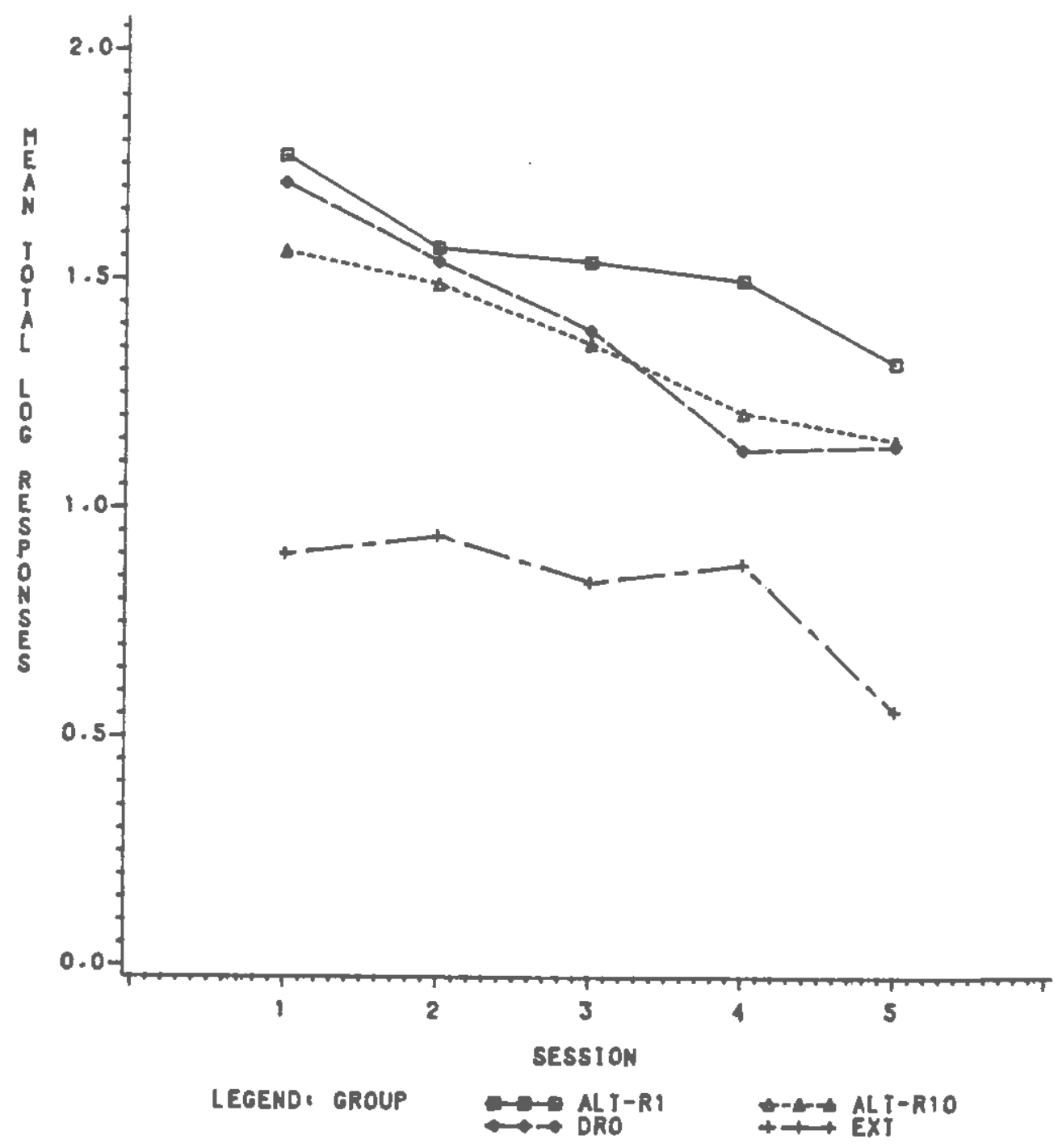




\section{Phase IV}

The means and standard deviations for the minute-by-minute totals for each group during the reacquisition phase are presented in Table 6. In this case, the Fmax test of homogeneity of variance was significant $(\underline{m} \max (9,60)=117.51, \mathrm{p}<.01)$, and as in the previous cases, a common log transformation was performed yielding the new means and standard deviations presented in Table 7. Here the $\underline{F} \max$ was also significant $(\underline{\operatorname{Fmax}}(9,20)=23.9)$. The summary table of the mixed design anOVA for the common log transformed data is presented in ppendix D. In this case the main effect for treatments was nonsignificant $\underline{F}(3,36)=1.25, \underline{P}>.05)$ and both the main effect for time and the treatments $x$ time interaction effects were significant at the $\mathrm{p}<.001$ level $(\underline{F}(14,504)=42.20$ and $\underline{F}(42,504)=2.95$, respectively).

A graph of the means of the common log transformed data for the reacquisition phase is presented in Figure 4. At minute 1, no significant differences between groups were found $(\underline{F}(3,86)=2.16, p>.05)$; however, at minutes 2,3 , and 4 , significant differences were found at the $p<.01$ level $(\underline{F}(3,86)=7.13$ at minute $2, \underline{F}(3,86)=7.30$ at minute 3 , and $\underline{F}(3,86)=5.52$ at minute 4$)$. No other significant differences were found. The $\underline{F}$ value for minute 5 was 1.82 and for minute 6 was 1.66 ( $\underline{\underline{f}}=3.86 ; p>.05$ ). Beyond minute 6 all $E$ values were less than 1.00 . 
Newman-Kuels follow-up test vere performed across treatments for minutes 2, 3, and 4. At minutes 2 and 3 , all pairwise comparisons were found to be significant $(\mathrm{p}<.01$ at minute 2 and $\mathrm{p}<.05$ at minute 3). Finally, at minute 4. all group comparisons were significantly different from one another ( $\mathrm{p}<.01$ except for EXT vs. DRO ( $\mathrm{p}<.05)$.

Given the pattern of means shown in Figure 4, these results indicate that reacquisition proceeded very rapidly for all groups, but that in the first few minutes of the session some differences occurred between groups. The primary result was that subjects in both ALT-R1 and ALT-R10 groups were consistently quicker to reacquire the original lever response than subjects in either the DRO or EXT groups. A second and slightly less robust result was that, in two of the three minutes where significant differences were found, DRO showed a significantly higher rate of response than EXT.

In order to assess the practical significance of the effects found in Phase IV, Omega squared values were calculated for each effect. The nonsignificant treatments effect yielded a value of .01 , and the time effect and time $x$ treatments interaction vere .41 and .08 respectively. This pattern of resuits indicates that, while the interaction effect found in minutes 2 through 4 was of considerable theoretical importance, it represents only $8 \%$ of the variance in this design. 
Table 6

Heans and standard Deviations of Total 1 original_Lever Besponses per Winute for Each Group During the Fifteen innutes of the Reacquisition Phase

\section{Group}

Uin. Hean S.D. Hean S.D. Mean $\frac{\text { EXT }}{\text { S.D. }}$ Hean S.D.

\begin{tabular}{rrrrrrrrrr}
\hline 1 & 1.40 & 3.78 & 4.00 & 4.76 & 5.80 & 7.07 & 1.70 & 2.16 \\
2 & 3.20 & 5.61 & 9.30 & 7.40 & 18.10 & 19.58 & 5.30 & 6.32 \\
3 & 6.30 & 7.96 & 17.80 & 11.02 & 20.60 & 21.11 & 7.10 & 7.82 \\
4 & 7.20 & 7.91 & 20.70 & 10.01 & 19.50 & 16.60 & 11.02 & 10.17 \\
5 & 12.30 & 9.07 & 15.80 & 9.82 & 23.60 & 20.07 & 13.00 & 12.18 \\
6 & 15.60 & 9.92 & 21.60 & 7.68 & 22.50 & 23.45 & 12.10 & 10.29 \\
7 & 18.20 & 8.73 & 19.60 & 7.06 & 23.40 & 21.64 & 13.30 & 11.92 \\
8 & 18.30 & 8.86 & 18.20 & 8.23 & 23.50 & 19.43 & 13.60 & 9.06 \\
9 & 21.00 & 10.08 & 18.20 & 8.46 & 26.40 & 22.52 & 17.30 & 9.42 \\
10 & 18.20 & 8.31 & 21.60 & 8.75 & 25.10 & 19.81 & 18.20 & 11.65 \\
11 & 17.60 & 8.57 & 19.40 & 7.15 & 23.10 & 16.97 & 16.50 & 9.05 \\
12 & 19.60 & 7.31 & 19.80 & 10.00 & 25.50 & 20.21 & 20.60 & 11.58 \\
13 & 19.70 & 7.13 & 18.10 & 7.75 & 25.30 & 18.61 & 19.20 & 9.85 \\
14 & 22.30 & 7.71 & 17.40 & 4.74 & 25.10 & 18.04 & 18.30 & 11.58 \\
15 & 17.20 & 7.77 & 18.50 & 6.93 & 26.50 & 19.62 & 19.40 & 9.85 \\
\hline & & & & & & & & \\
\hline & 11.56 \\
\hline
\end{tabular}


Table 7

Means_and_standard Deviations_of Common Ioq Transformed Tota 1 original Lever Responses per 브므늘 for

Each Group During the Beacquisition Phase

Group

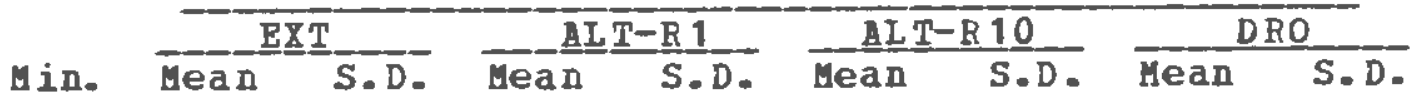

$\begin{array}{lllllllll}1 & 0.16 & 0.37 & 0.50 & 0.44 & 0.56 & 0.55 & 0.30 & 0.35\end{array}$

$\begin{array}{lllllllll}2 & 0.33 & 0.49 & 0.89 & 0.36 & 1.09 & 0.48 & 0.56 & 0.50\end{array}$

$\begin{array}{lllllllll}3 & 0.53 & 0.60 & 1.22 & 0.21 & 1.11 & 0.53 & 0.64 & 0.55\end{array}$

$\begin{array}{lllllllll}4 & 0.63 & 0.57 & 1.30 & 0.20 & 1.15 & 0.48 & 0.84 & 0.57\end{array}$

$\begin{array}{lllllllll}5 & 0.93 & 0.54 & 1.17 & 0.22 & 1.21 & 0.51 & 0.87 & 0.61\end{array}$

$\begin{array}{lllllllll}6 & 1.07 & 0.47 & 1.33 & 0.16 & 1.16 & 0.52 & 0.94 & 0.48\end{array}$

$\begin{array}{lllllllll}7 & 1.20 & 0.34 & 1.29 & 0.14 & 1.21 & 0.50 & 1.00 & 0.44\end{array}$

$\begin{array}{lllllllll}8 & 1.18 & 0.43 & 1.25 & 0.16 & 1.21 & 0.50 & 1.08 & 0.33\end{array}$

$\begin{array}{lllllllll}9 & 1.23 & 0.45 & 1.25 & 0.18 & 1.29 & 0.50 & 1.17 & 0.36\end{array}$

$\begin{array}{lllllllll}10 & 1.22 & 0.29 & 1.32 & 0.19 & 1.25 & 0.50 & 1.15 & 0.45\end{array}$

$\begin{array}{lllllllll}11 & 1.22 & 0.24 & 1.29 & 0.15 & 1.23 & 0.49 & 1.16 & 0.35\end{array}$

$\begin{array}{lllllllll}12 & 1.28 & 0.18 & 1.28 & 0.18 & 1.25 & 0.50 & 1.25 & 0.33\end{array}$

$\begin{array}{lllllllll}13 & 1.29 & 0.18 & 1.25 & 0.16 & 1.26 & 0.50 & 1.24 & 0.27\end{array}$

$\begin{array}{lllllllll}14 & 1.34 & 0.15 & 1.25 & 0.12 & 1.27 & 0.49 & 1.21 & 0.26\end{array}$

$\begin{array}{lllllllll}15 & 1.21 & 0.23 & 1.27 & 0.14 & 1.28 & 0.51 & 1.23 & 0.29\end{array}$ 
Pigure 4. Mean common log transformed total original lever responses per min for each treatment group across the 15 mins of the reacquisition phase. 


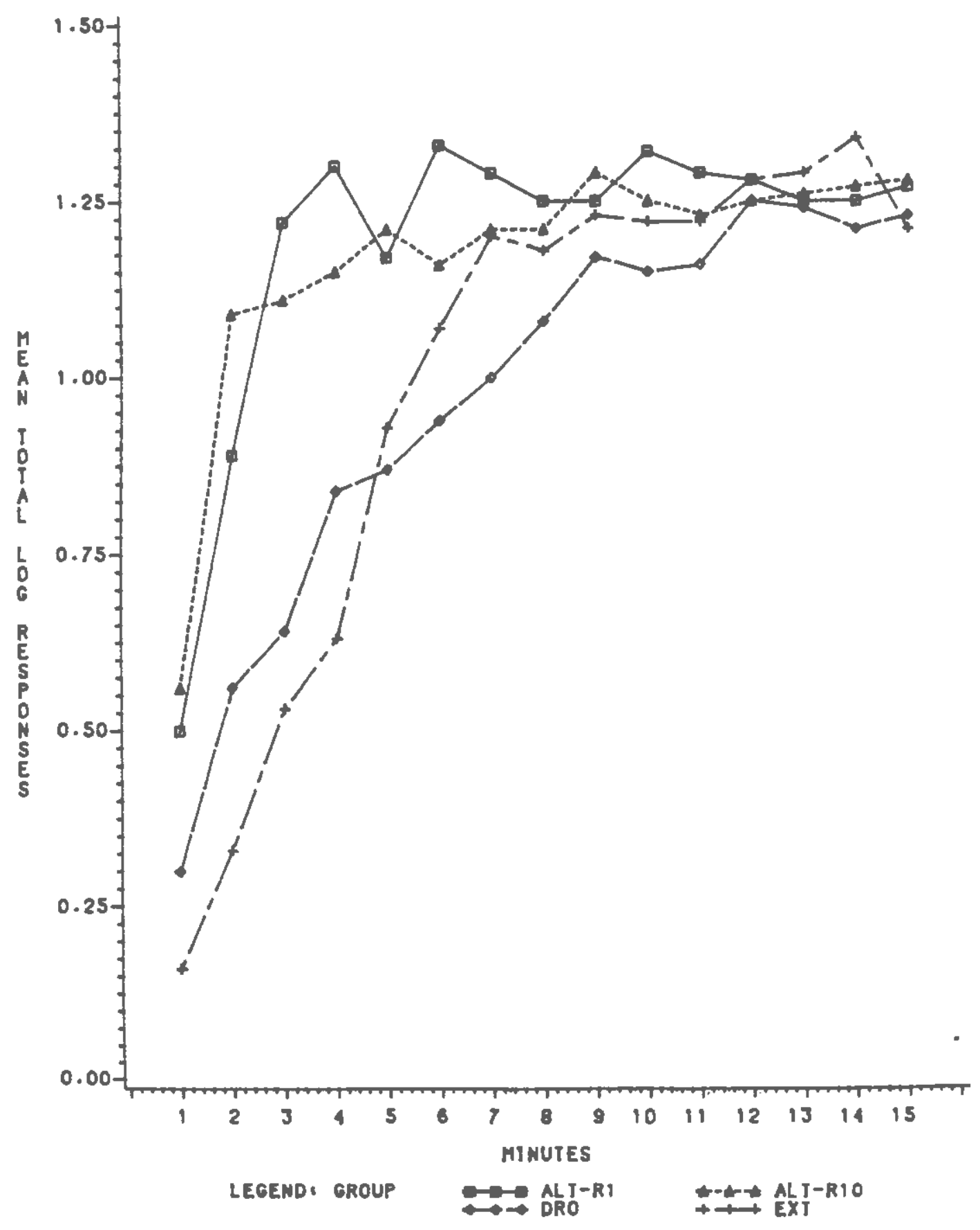


Savings Analysis

since Leitenberg, et al. (1975) and Pacitti and smith (1977) analyzed total original lever responses across both the treatment and extinction phases in order to determine whether any of the reinforcement-based procedures produced a significant "savings" in total responses emitted across these phases, a similar analysis was performed for the data collected in the present study. Table 8 shows the means and standard deviations for total original lever responses for each group across phases II and III. A Hartley's test of homogeneity of variance proved nonsignificant (Fmax (4, 9) = 7.04) as did the analysis of variance for differences between groups $(E(3,36)<1.00$; see summary table, Appendix E) indicating no difference in total responses. 
Table 8

Means and Standard Deviations for Total original

Lever Responses for each Group Across Phases II and III

\begin{tabular}{|c|c|c|c|c|}
\hline \multicolumn{5}{|c|}{ Group } \\
\hline & $\mathrm{EXT}$ & $\mathrm{ALT}-\mathrm{R} 1$ & $\mathrm{ALT}-\mathrm{R} 10$ & $\overline{D R O}$ \\
\hline Hean & 393.20 & 458.40 & 453.70 & 534.5 \\
\hline S.D. & 135.27 & 125.78 & 121.48 & 322.35 \\
\hline
\end{tabular}




\section{Alternate Iever Analyses}

While responses on the original lever was the dependent variable of major importance, an analysis of responses on the alternate lever was undertaken in order to gain a better understanding of the preceding results.

\section{Phase I--Training}

The means and standard deviations for alternate lever responses for each group across the five sessions of the training phase are presented in Table 9. The Hartley's test for these data yas significant $(\underline{F} m(20,9)=84.45)$ : hovever, after common log transformation a second test was no longer significant $(\underline{\max }(20,9)=5.18)$. The transformed means and standard deviations are presented in Table 10.

The mixed design analysis of variance for the common log transformed total alternate lever responses per session for each group across the five sessions of the training phase produced no significant effects. The $\underline{P} \mathbf{v}$ alues for $t h e$ treatments and sessions effects yere less than one, and the $\underline{P}$ for the treatment $x$ sessions interaction effect yas 1.22 $(\underline{\mathrm{d}} \underline{\underline{y}}=12,144 ; \quad p>.05)$. The summary table for this analysis is presented in Appendix $\mathbf{F}$. 
Table 9

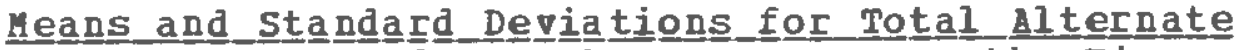
Lever_Besponses for each Group Acrosss_the Five Sessions of the Training Phases

\section{Session}

Group $\quad \frac{1}{4} \quad-\frac{5}{5}$

EXT

$\begin{array}{lrrrrr}\text { Mean } & 7.10 & 10.10 & 5.90 & 6.40 & 4.30 \\ \text { S.D } & 11.44 & 14.52 & 8.56 & 9.82 & 7.20\end{array}$

ALT-R 1

$\begin{array}{llllll}\text { Sean } & 2.60 & 2.30 & 3.00 & 2.40 & 3.80 \\ \text { S.D. } & 2.41 & 2.31 & 2.40 & 1.58 & 3.79\end{array}$

ALT-R 10

$\begin{array}{llllll}\text { Mean } & 2.20 & 2.20 & 1.40 & 2.80 & 2.20 \\ \text { S.D. } & 3.58 & 2.86 & 1.58 & 2.82 & 3.68\end{array}$

DRO

$\begin{array}{llllll}\text { Uean } & 2.90 & 3.80 & 2.00 & 3.00 & 2.00 \\ \text { S. D. } & 4.04 & 8.43 & 3.74 & 6.48 & 3.40\end{array}$


Table 10

Heans and Standard Deviations for Common_log

Trans formed alternate lever Responses_acrosos the

Five Sessions of the Training phase

\begin{tabular}{|c|c|c|c|c|c|}
\hline \multirow[b]{2}{*}{ Group } & \multicolumn{5}{|c|}{ Session } \\
\hline & 1 & 2 & 3 & 4 & 5 \\
\hline \multicolumn{6}{|l|}{$\mathrm{EXT}$} \\
\hline $\begin{array}{l}\text { Mean } \\
\text { S.D. }\end{array}$ & $\begin{array}{l}0.51 \\
0.60\end{array}$ & $\begin{array}{l}0.70 \\
0.57\end{array}$ & $\begin{array}{l}0.51 \\
0.56\end{array}$ & $\begin{array}{l}0.51 \\
0.58\end{array}$ & $\begin{array}{l}0.35 \\
0.57\end{array}$ \\
\hline \multicolumn{6}{|l|}{$A L T-R 1$} \\
\hline $\begin{array}{l}\text { Mean } \\
\text { S. D. }\end{array}$ & $\begin{array}{l}0.44 \\
0.36\end{array}$ & $\begin{array}{l}0.44 \\
0.26\end{array}$ & $\begin{array}{l}0.51 \\
0.32\end{array}$ & $\begin{array}{l}0.47 \\
0.27\end{array}$ & $\begin{array}{l}0.52 \\
0.42\end{array}$ \\
\hline \multicolumn{6}{|l|}{$A L T-R 10$} \\
\hline $\begin{array}{l}\text { Hean } \\
\text { S.D. }\end{array}$ & $\begin{array}{l}0.32 \\
0.40\end{array}$ & $\begin{array}{l}0.35 \\
0.39\end{array}$ & $\begin{array}{l}0.29 \\
0.31\end{array}$ & $\begin{array}{l}0.46 \\
0.34\end{array}$ & $\begin{array}{l}0.31 \\
0.40\end{array}$ \\
\hline $\begin{array}{l}\text { DRO } \\
\text { Hean } \\
\text { S.D. }\end{array}$ & $\begin{array}{l}0.41 \\
0.41\end{array}$ & $\begin{array}{l}0.34 \\
0.49\end{array}$ & $\begin{array}{l}0.29 \\
0.38\end{array}$ & $\begin{array}{l}0.32 \\
0.44\end{array}$ & $\begin{array}{l}0.31 \\
0.38\end{array}$ \\
\hline
\end{tabular}




\section{Phase II--Treatmengt}

The means and standard deviations for total alternate lever responses per session in the five sessions of the treatment phase for each of the four treatment groups is presented in Table 11. Once again the Hartley's test of homogeneity of variance was significant $(\underline{F} m a x(20,9)=$ 9,443.03). A common log transformation of these data produced the means and standard deviations presented in Table 12. An Fmax test of the transformed data was still significant $(\underline{F} \max (20,9)=94.25)$.

The summary table for the mixed design analysis of variance of the common log transformed alternate lever responses during the treatment phase is presented in Appendix G. Both main effects and the interaction effect were significant beyond the $\mathrm{P}<.001$ level $(\underline{F}(3,36)=38.90$ fr treatments. $\underline{F}(4,144)=9.59$ for sessions, and $\underline{F}(12,144)$ $=8.00$ for sessions $x$ treatments interaction). A graph of the mean rate of alternate lever responses for each group across the five sessions of Phase II is presented in Figure 5. which shows a rapid increase in log response rate for the ALT-R1 and ALT-R10 groups with relatively low, even rates of responding in the other two groups.

Simple effects tests conducted at all levels of sessions yielded significant differences at the $\mathrm{P}<.01$ level $(F(3,86)=8.54$ at session 1: $\underline{F}(3,86)=15.53$ at session 2; $\underline{F}(3,86)=28.56$ at session $3 ; \underline{F}(3,86)=38.82$ 
at session 4: and $\underline{\underline{F}}(3,86)=44.43$ at session 5$)$.

Newman-Kuels follow-up tests at each level of sessions revealed a changing pattern of differences among treatment groups. At session 1 and 2 , all treatments vere significantly different from each other $(p<.05)$ except for the EXT VS. DRO comparisons. At session 3, all four groups were significantly different from each other at the $p<.05$ level. At sessions 4 and 5, ALT-R1 and ILT-R10 were no longer significantly different from one another, and at session 5 EXT and DRO were once again not significantly different. All other comparisons in the last two sessions were significantly different from one another (p<-05). Finally omega square values were calculated for the treatment, sessions, and treatment $x$ sessions effects. The values obtained were .25 for treatments, . 09 for sessions, and .21 for treatments $x$ sessions. These results suggest that the largest part of the variance in this design can be attributed to the treatment and treatment $x$ sessions effects, reflecting the increasing rate of $\mathrm{log}$ responses for the ALT-K1 and ALT-R10 groups. 
Table 11

Means and standard Deviations of potal Alternate Lever Responses for each Group During the

Five sessions of the Treatment Phase

\begin{tabular}{|c|c|c|c|c|c|}
\hline \multirow[b]{2}{*}{ Group } & \multicolumn{5}{|c|}{ Sessions } \\
\hline & 1 & 2 & 3 & 4 & 5 \\
\hline \multicolumn{6}{|l|}{$\mathrm{EXT}$} \\
\hline Hean & 7.20 & 9.70 & 5.50 & 4.90 & 2.30 \\
\hline S. D. & 9.69 & 7.73 & 6.17 & 6.40 & 2.21 \\
\hline \multicolumn{6}{|l|}{ AL T-R 1} \\
\hline Lean & 69.60 & 180.50 & 212.20 & 238.10 & 263.20 \\
\hline S.D. & 35.82 & 79.15 & 54.84 & 55.02 & 55.81 \\
\hline \multicolumn{6}{|l|}{ ALT-R 10} \\
\hline Sean & 32.30 & 134.90 & 213.80 & 311.20 & 352.00 \\
\hline S. D. & 35.08 & 172.65 & 180.46 & 215.20 & 205.95 \\
\hline \multicolumn{6}{|l|}{ DBO } \\
\hline Mean & 7.70 & 9.90 & 15.50 & 6.30 & 6.60 \\
\hline S.D. & 8.56 & 16.09 & 27.24 & 7.65 & 7.06 \\
\hline
\end{tabular}


Table 12

yeans and standard Deviations of Common Log Transformed Total Alternate Lever Responses During the Five sessions of the Treatment phase

\begin{tabular}{|c|c|c|c|c|c|}
\hline \multirow[b]{2}{*}{ Group } & \multicolumn{4}{|c|}{ Sessions } & \multirow[b]{2}{*}{5} \\
\hline & 1 & 2 & 3 & 4 & \\
\hline \multicolumn{6}{|l|}{$\mathrm{EXT}$} \\
\hline vean & 0.66 & 0.89 & 0.57 & 0.56 & 0.42 \\
\hline S.D. & 0.50 & 0.40 & 0.52 & 0.47 & 0.33 \\
\hline \multicolumn{6}{|l|}{$A L T-R 1$} \\
\hline Mean & 1.71 & 2.16 & 2.31 & 2.37 & 2. 41 \\
\hline S. D. & 0.52 & 0.41 & 0.13 & 0.10 & 0.09 \\
\hline \multicolumn{6}{|l|}{$A L T-R 10$} \\
\hline Eean & 1. 12 & 1.51 & 2.01 & 2.33 & 2.46 \\
\hline S.D. & 0.75 & 0.93 & 0.77 & 0.53 & 0.32 \\
\hline \multicolumn{6}{|l|}{ DRO } \\
\hline Mead & 0.72 & 0.74 & 0.74 & 0.58 & 0.66 \\
\hline S. D. & 0.47 & 0.53 & 0.70 & 0.56 & 0.50 \\
\hline
\end{tabular}


Figure 5. A graph of mean common log transformed alternate lever responses for each group during the five sessions of the treatment phase. 


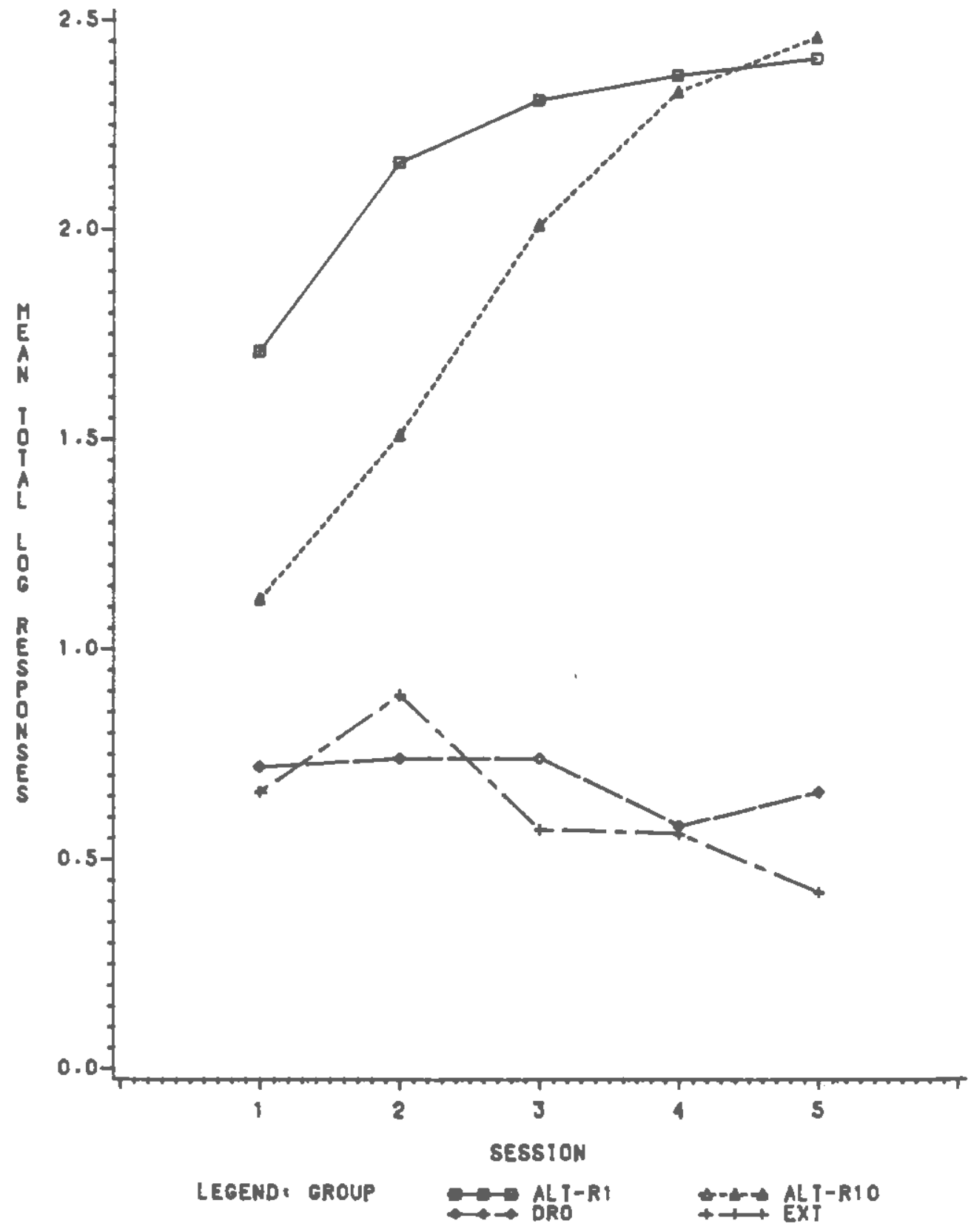




\section{Phase III--Extinction}

The means and standard deviations for total alternate lever responses for each group across the five sessions of the extinction phase are presented in Table 13. Again a Hartley's test of homogeneity of variance was significant $(\underline{F} \max (20,9)=1,763.24)$. A common $\log$ transformation of these data produced homogeneity (Fmax $(20,9)=11.54)$, and the following analysis was performed on the transformed data. The means and standard deviations for total common $\log$ responses is presented in Table 14.

Figure 6 is a graph of the means for total log alternate lever responses for each group during the five sessions of the extinction phase. The analysis of variance sumary table for these data is presented in Appendix $H$. The analysis reveals significant effects for treatments $(\underline{E}(3,36)=68.21, \underline{p}<.001$, sessions $(\underline{E}(4,144)=24.11, \mathrm{~g}$ $<.001$, and sessions $x$ treatments $(\underline{F}(12,144)=2.76, p<$ $.01)$

11 five simple effects tests across groups at each level of sessions revealed significant effects at the $p<$ .001 level $(\underline{F}(3,125)=55.11$ at session $1 ; \underline{F}(3,125)=$ 38.19 at session $2 ; \underline{F}(3,125)=34.24$ at $\operatorname{session} 3 ; \underline{F}(3$, $125)=21.68$ at session $4 ;$ and $\underline{F}(3,125)=16.73$ at session 5).

Newman-Kuels follow-up tests produced a fairly consistent pattern of differences between groups. In 
sessions 1 through 4, all pairs vere significantly different fror one another $(\mathrm{p}<.05)$ except the ALT-R 1 is. ALT-R10 comparison. By session 5, all pairs were significantly different from one another $(p<.05)$. This result suggests that ALT-R1 and ALT-R10 maintained a consistentIy higher rate of $\log$ alternate lever responses than the other treatment groups and that the DRO group showed a consistently higher rate than the EXT group.

Pinally, the effect sizes for this analysis vere estimated by calculating the appropriate omega squared values. They vere: .391 for the treatments effect, .179 for the sessions effect, and .041 for the sessions $x$ treatments interaction. This result indicates that the most important ingredient in this analysis was the group effect, which accounted for approximately $40 \%$ of the variance. 
Table 13

Heans and stang dard Deviations for Total 1lternate Lever Responses for Each Group During the Five sessions of the Extinction Phase

Sessions

Group

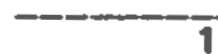

1

3

4

5

EXT

$\begin{array}{llllll}\text { Hean } & 2.30 & 2.70 & 2.40 & 2.60 & 2.20 \\ \text { S.D. } & 2.21 & 3.09 & 3.24 & 3.81 & 5.27\end{array}$

ALT-R 1

$\begin{array}{rrrrrr}\text { Hean } & 148.90 & 76.00 & 51.40 & 27.80 & 25.40 \\ \text { S.D. } & 62.10 & 30.83 & 18.02 & 15.59 & 20.06\end{array}$

$A L T-R 10$

Hean

156.80

82.00

92.97

66.51

75.50

34. 10

14.70

S. D.

18.30

11.40

16.72

10.62

13.10
15.22

6.90

4.63

5.70

S.D.

15. 22

6.48 
Table 14

ㅂẹans and standard Deviations of Common Iog

Trang formed Alternate Lever Responses_for ea ch

Group Across the Five session of the

Extinction Phase

Sessions

Group $1 \frac{3}{4} \quad 35$

EXT

$\begin{array}{llllll}\text { Hean } & 0.42 & 0.41 & 0.35 & 0.35 & 0.25 \\ \text { S. D. } & 0.33 & 0.40 & 0.41 & 0.43 & 0.41\end{array}$

ALT-R 1

$\begin{array}{llllll}\text { Hean } & 2.14 & 1.85 & 1.69 & 1.41 & 1.29 \\ \text { S.D. } & 0.19 & 0.20 & 0.16 & 0.21 & 0.36\end{array}$

ALT-R 10

$\begin{array}{llllll}\text { Hean } & 2.13 & 1.81 & 1.75 & 1.46 & 1.14 \\ \text { S.D. } & 0.26 & 0.32 & 0.38 & 0.33 & 0.22\end{array}$

DRO

$\begin{array}{llllll}\text { Lean } & 1.05 & 0.90 & 0.93 & 0.77 & 0.67 \\ \text { S.D. } & 0.55 & 0.47 & 0.47 & 0.42 & 0.38\end{array}$


Pigure 6. Hean $10 \mathrm{~g}$ transformed total alternate lever responses per session for each group across the five sessions of the extinction phase. 


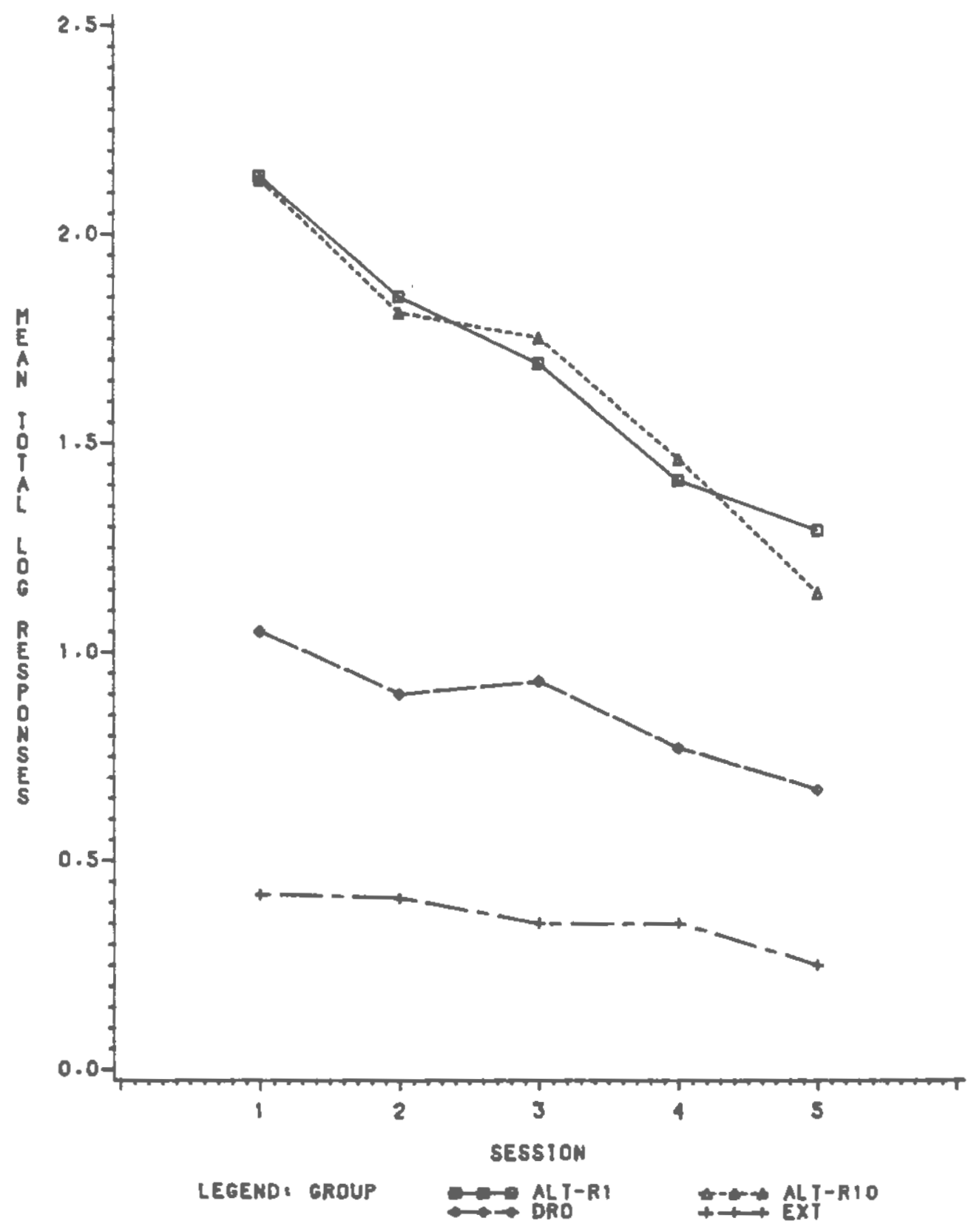




\section{Phase IV=-Reacquisition}

The means and standard deviations for total alternate lever responses per minute for each group across the 15 mins of the reacquisition phase are presented in Table 17. Because several cells had standard deviations of zero, the Hartley's Fmax test was not an appropriate test of homogeneity of variance. As a result, a Cochran's test was performed on the data in Table 15, yielding a $\underline{c}(60,9)$ value of .200 which was significant. A common $\log$ transformation was performed on the alternate lever reacquisition data, and the means and standard deviations for the resulting data are presented in Table 16. A Cochran's test was performed on the transformed data and, in this case, produced a $\underline{\mathbf{C}}(60,9)$ of .070, which is still significant. A graph of the mean common $\log$ tranformed alternate lever responses per minute for Phase IV is presented in Figure 7.

The mixed design ANOVA summary table for the analysis of total log transformed alternate lever responses per minute is presented in Appendix I. Significant effects were obtained for treatments $\underline{F}(3,36)=3.35, \mathrm{p}<.05)$, time $\underline{F}(14,504)=4.25, \underline{p}<.001)$, and time $x$ treatments $(\underline{F}(42$, $504)=2.68, \mathrm{p}<.001)$.

Simple effects tests were performed across groups at all levels of time, and where significant differences were found, Newman-Kuels follow-up tests were done to locate differences between means. Simple effects tests at minutes 
1 and 2 produced $\underline{F}$ values of 14.01 ( $\underline{\underline{f}} \underline{f}=3,275 ; p<.01$ ) and 7.70 ( $\underline{\underline{f}}=3.275 ; p<.01)$ respectively. Newman-Kuels tests revealed that, in both cases, all pairs of group means were significantly different from one another except for the DRO vS. ALT-R10 comparison for minute 1 and DRO vS. EXT for minute 2 .

At minute 3, the simple effects test was not significant $(\underline{F}(3,275)=1.90, \underline{p}>.05)$. Hovever, minutes 4 through 8 vere significant at the $\mathrm{p}<.05$ level $(\mathrm{F}(3,275)=$ 3.96 at minute $4, \underline{F}(3,275)=2.92$ at minute $5, \underline{E}(3,275)=$ 3.20 at minute $6, \underline{F}(3,275)=2.83$ at minute 7 , and $\underline{\underline{F}}(3$, $275)=3.34$ at minute 8 ). At minutes 9 through 15, simple effects tests yielded no significant differences. For minute 9, $\underline{\mathrm{F}}(3,275)=1.46(\mathrm{p}>.05)$, and for minutes 10 through 15, all $\underline{\mathrm{F}}$ values vere < 1.0. A Newman-Kuels follow-up test at min 4 revealed that all group comparisons vere significant $(p<.05)$ except DRO vS. EXT and ALT-R 1 vs. ALT-R10. For both minutes 5 and 6, ALT-R10 was significantly different from all other groups $(p<.05)$, but no other comparisons were significant. At minute 7, all pairs vere significantly different except DRO vs. EXT and ALT-R1 vs. EXT. Finally, at minute 8 , all groups vere significantly different from each other $(p<.05)$ except DRO vs. EXT and ALT-R1 vs. ALT-R10.

Omega squared values were calculated to determine the effect size of the alternate lever analysis in the 
reacquistion phase. The values vere .010 for treatments. .063 for time, and .098 for time $x$ treatments. In this case the interaction effect, which was of primary interest, represented approximately $10 \%$ of the total variance. 
Table 15

Heans and Standard Deviations of Total 1 iternate Lever Responses for each Group bcross the Fifteen ginutes of the Reacgu istion Phase

Group

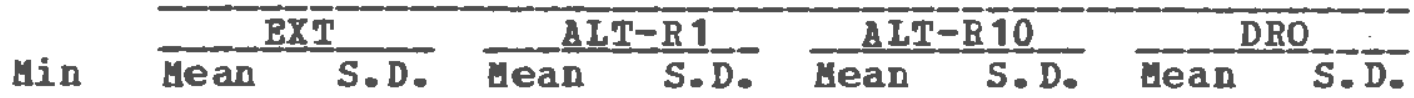

$0.10 \quad 0.32$

$5.10 \quad 4.86$

2.30

3.53

$0.20 \quad 0.42$

2

$0.20 \quad 0.63 \quad 4.50 \quad 5.30$

$2.60 \quad 4.30$

$0.10 \quad 0.32$

3

$0.80 \quad 1.75$

$2.00 \quad 2.16$

2.70

5.23

$0.90 \quad 1.72$

4

$0.10 \quad 0.32$

$1.50 \quad 2.01$

3.30

8.03

$0.00 \quad 0.00$

5

$0.10 \quad 0.32$

$0.60 \quad 1.07$

$4.60 \quad 10.97$

$0.10 \quad 0.32$

6

$0.20 \quad 0.42$

$0.50 \quad 0.97$

$4.60 \quad 10.50$

$0.20 \quad 0.63$

7

$0.20 \quad 0.42$

$0.80 \quad 1.75$

$3.40 \quad 7.73$

$0.00 \quad 0.00$

8

$0.00 \quad 0.00$

$2.30 \quad 3.89$

$1.40 \quad 3.44$

$0.00 \quad 0.00$

9

$0.10 \quad 0.32$

$1.80 \quad 3.91$

$0.00 \quad 0.00$

$1.80 \quad 5.69$

10

$0.00 \quad 0.00$

$0.40 \quad 0.52$

$0.10 \quad 0.32$

$1.00 \quad 2.83$

11

$0.10 \quad 0.32$

$0.20 \quad 0.63$

$0.10 \quad 0.32$

$0.80 \quad 2.53$

12

$0.20 \quad 0.63$

$0.40 \quad 0.70$

$0.40 \quad 1.26$

$0.30 \quad 0.67$

13

$0.00 \quad 0.00$

$0.40 \quad 0.52$

$0.40 \quad 1.26$

$0.90 \quad 2.51$

14

$0.10 \quad 0.32$

$0.10 \quad 0.32$

$0.20 \quad 0.42$

$0.90 \quad 2.51$

15

$0.20 \quad 0.63$

$0.00 \quad 0.00$

$0.10 \quad 0.32$

$0.80 \quad 2.53$ 
Table 16

עeans and Standa믐 Deviations_of Common Iog

Transformed Total Alternate lever Responses for each Group Across the Fifteen

\section{Beacquisition Phase}

\section{Group}

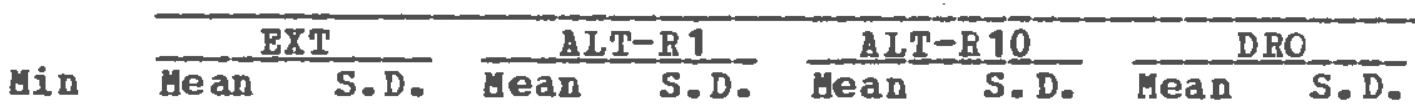

\begin{tabular}{|c|c|c|c|c|c|c|c|c|}
\hline 1 & 0.03 & 0.10 & 0.70 & 0.27 & 0.31 & 0.43 & 0.06 & 0.13 \\
\hline 2 & 0.05 & 0.15 & 0.51 & 0.50 & 0.31 & 0.45 & 0.03 & 0.10 \\
\hline 3 & 0.14 & 0.29 & 0.36 & 0.34 & 0.33 & 0.42 & 0.17 & 0.29 \\
\hline 4 & 0.03 & 0.10 & 0.28 & 0.33 & 0.32 & 0.45 & 0.00 & 0.00 \\
\hline 5 & 0.03 & 0.10 & 0.14 & 0.23 & 0.33 & 0.53 & 0.00 & 0.10 \\
\hline 6 & 0.06 & 0.13 & 0.12 & 0.21 & 0.36 & 0.53 & 0.05 & 0.15 \\
\hline 7 & 0.06 & 0.13 & 0.14 & 0.29 & 0.32 & 0.48 & 0.00 & 0.00 \\
\hline 8 & 0.00 & 0.00 & 0.31 & 0.42 & 0.18 & 0.36 & 0.00 & 0.00 \\
\hline 9 & 0.03 & 0.10 & 0.12 & 0.40 & 0.03 & 0.00 & 0.13 & 0.40 \\
\hline 10 & 0.03 & 0.00 & 0.05 & 0.16 & 0.03 & 0.10 & 0.10 & 0.32 \\
\hline 11 & 0.03 & 0.10 & 0.05 & 0.16 & 0.03 & 0.10 & 0.10 & 0.32 \\
\hline 12 & 0.05 & 0.15 & 0.11 & 0.18 & 0.07 & 0.22 & 0.08 & 0.17 \\
\hline 13 & 0.00 & 0.00 & 0.12 & 0.16 & 0.07 & 0.22 & 0.12 & 0.31 \\
\hline 14 & 0.03 & 0.10 & 0.03 & 0.10 & 0.06 & 0.13 & 0.12 & 0.31 \\
\hline 15 & 0.05 & 0.15 & 0.00 & 0.00 & 0.03 & 0.10 & 0.10 & 0.30 \\
\hline
\end{tabular}


Pigure 7. Bean common log transformed total alternate lever responses per minute for each group across the fifteen ninutes of the reacquisition phase. 


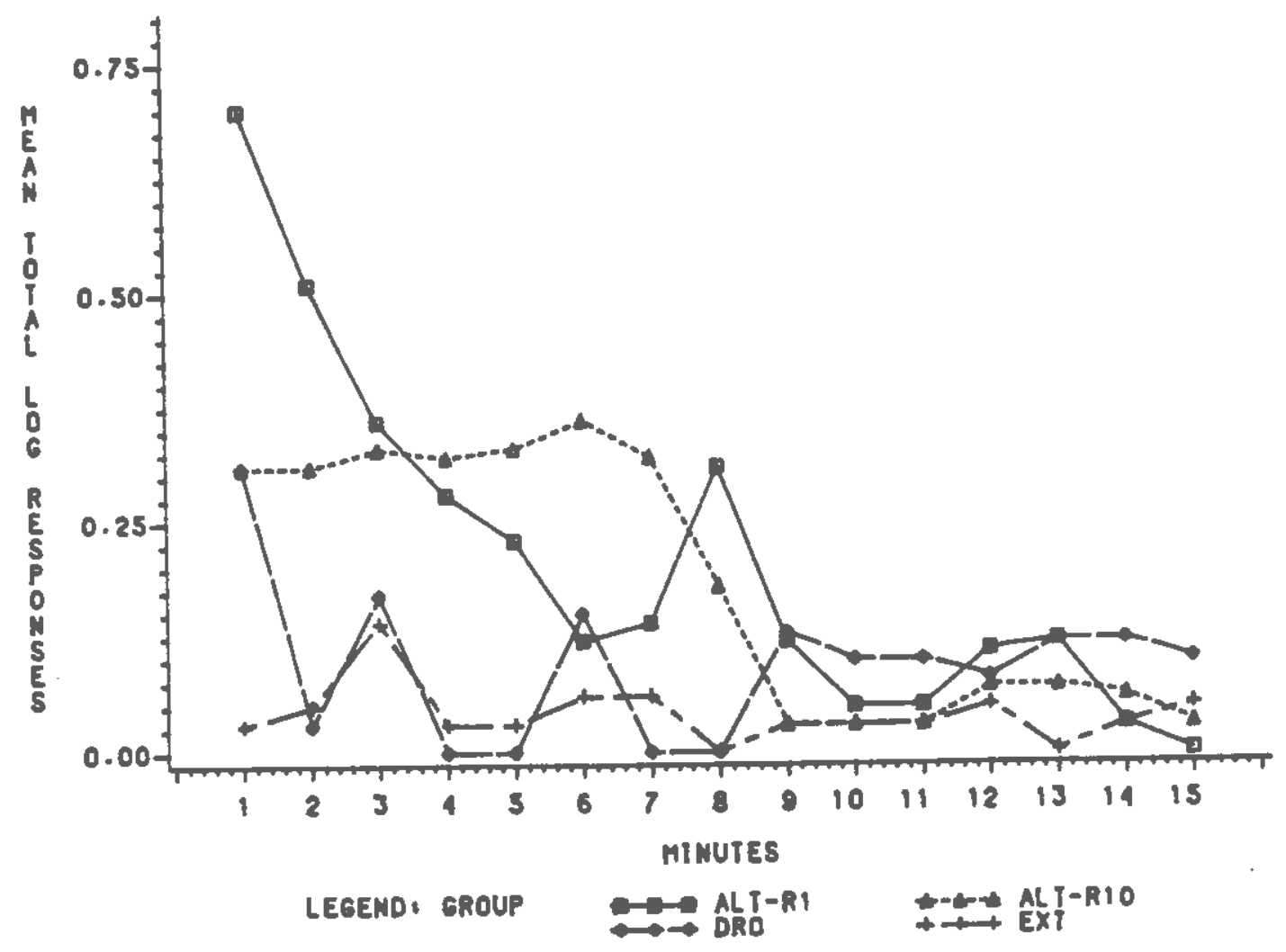




\section{Reinforce ment Rate Analyses}

In order to assess the contribution of the amount of obtained reinforcement to the effectiveness of each reinforcement-based procedure, an analysis of total reinforcements per session was undertaken for Phases I and II, as well as reinforcements per minute in Phase IV.

\section{Phase I--Training}

Table 17 shows the means and standard deviations for total reinforcements per session for each treatment group across the five sessions of the training phase. A Hartley's test of homogeneity of variance yielded a value of $\underline{\text { max }} \mathbf{2 0}$. 9) $=13.43$, which was nonsignificant. The analysis of variance for these data produced nonsignificant effects for treatments and sessions $x$ treatments interaction (both $\underline{F}$ values < 1.0) and a significant effect for sessions ( $F(4$, 144) $=40.83 . p<.0011$. The summary table for this analysis is presented in Appendix $J$. This result established that, like the previous two dependent variables, no significant differences in rate of reinforcement were observed across groups at any point in Phase I.

An Omega square value was calculated for the single significant effect, yielding . 37 for sessions. 
Table 17

Leans and Standard Deviations for Total Beinforcements For each Group across the Five Sessions of the

Training Phase

\section{Session}

Group

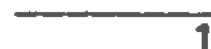

12

3

4

5

EXT

$\begin{array}{rrrrrr}\text { Lean } & 69.30 & 72.90 & 74.80 & 77.10 & 80.90 \\ \text { S.D. } & 8.30 & 11.36 & 8.60 & 8.77 & 6.33\end{array}$

AIT-R 1

$\begin{array}{rrrrrr}\text { Hean } & 68.70 & 71.90 & 74.20 & 77.10 & 80.30 \\ \text { S. D. } & 4.37 & 7.00 & 5.33 & 3.72 & 4.24\end{array}$

ALT-B 10

Hean

69.80

$73.00 \quad 75.80$

3.42

78.40
3.13

80.50

S.D.

11.52

5.81

5.46

DRO

Hean

S. D.

$\begin{array}{lll}68.60 & 74.10 & 76.30\end{array}$

$\begin{array}{lll}10.00 & 7.64 & 10.36\end{array}$

79.30
6.38

81.70

4.47 


\section{Phase II-二Treatment}

The means and standard deviations for total

reinforcements per session for the ALT-B1, ALT-R10, and DRO groups are presented in Table 21. A Hartley's test of homogeneity of variance for these data was significant $(\underline{F} \max (15,9)=81.69 . \mathrm{p}<.01)$. An arcsin tranformation was performed on these data (after dividing each value by 90. the total possible reinforcements per session, to produce proportions), and the transformed values are presented in Table 19. The $\underline{\underline{P} m a x}$ for these data was 30.16 ( $\underline{d \underline{f}}=15.9)$. which was still significant at the $p<.01$ level.

Appendix $K$ shows the summary table for the $3 \times 5$ mixed design analysis of variance of arcsin transformed reinforcement rate during the five sessions of the treatment phase for the three reinforcement-based procedures. The effects for treatments and sessions were both significant $\underline{E}(2,27)=7.68$ for treatments $(\underline{p}<.01)$ and $\underline{F}(4,108)=$ 97. 15 for sessions $(p<.001)$, but there was no significant sessions $x$ treatments interaction $(\underline{F}(8,108)=1.08, p>$ $.05)$.

The results of the analysis of variance are confirmed 
by Figure 8, a plot of the mean arcsin transformed rate of reinforcement for the three reinforcement-based response elimination procedures across the five sessions of phase III. The general trend for all groups is upuard with an apparent ly lower rate for the ALT-R10 group across all levels of sessions.

Simple effects tests were performed across groups at each level of sessions in order to determine whether the apparent differences in Figure 8 were significant. At sessions 1 through 3 , these tests were significant at the $p$ $<.01$ level $(\underline{F}(2,111)=9.30$ at session $1 ; \underline{F}(2,111)=$ 7. 12 at session $2:$ and $E(2,111)=8.71$ at session 3$)$. At session 4, there were significant differences at the $p<.05$ level $(\underline{F}(2,111)=3.42)$, and no significant differences were found at session $5(\underline{F}(2,111)=2.31)$. Newman-Kuels follow-up tests indicated that at session 1 all groups were significantly different from one another ( $p<.05)$ and that the same was true at sessions $3(p<.01)$ and $4(\mathrm{p}<.01)$. However, at session 2, DRO was not significantly different from ALT-R1. This pattern of results indicates a consistently lower rate of reinforcement for ALT-R10 than for either DRO or ALT-R1 (through session four). In addition, for three of the five sessions, DRO obtained a significantly higher rate of reinforcement than ALT-R1. BY session 5 all groups obtained equivalent rates of reinforcement. 
The Omega squared values for this analysis vere .024 for treatments, .701 for sessions, and .001 for sessions $x$ treatments. These results indicated that. while the significant treatment effect was of primary interest, it represented only $2 \%$ of the variance in this analysis. 
Table 18

Eeans and_standard Deviations of Total Reinforcements Per session for the Three Reinforcement-based Response Elimination Procedures Across the pire Sessions of the Trieatment phase

Session

Group

1

3

4

5

AL T-R 1

Lean

S.D

29.50

60.70

71.30

10.77

77.20
3.64

79.10

12.08

18.87

4. 35

AL T-B 10

bean

S. D.

$8.20 \quad 30.80$

48.60

63.80

69.90

11.4

32.90

30.01

$24.82 \quad 20.93$

DEO

Hean

S. D

38.00

16.36

60.90

20.75

78.80
7.70

81. 10

82.00

$7.22 \quad 7.76$


Table 19

Eeans and stạndara d Deviations of Arcsin

Transfor med Total Reinforcements per session

For the Three Reinforcement-based Response

Elimination Procedures Across the Five

Sessions of the Treatment phase

Session

Group $\quad \begin{array}{llll}1 & 2 & 3 & 4\end{array}$

\begin{tabular}{|c|c|c|c|c|c|}
\hline $\begin{array}{r}A L T-R 1 \\
\text { Lean } \\
S . D .\end{array}$ & $\begin{array}{l}0.34 \\
0.14\end{array}$ & $\begin{array}{l}0.76 \\
0.25\end{array}$ & $\begin{array}{l}0.93 \\
0.17\end{array}$ & $\begin{array}{l}1.04 \\
0.08\end{array}$ & $\begin{array}{l}1.08 \\
0.10\end{array}$ \\
\hline$\Delta L T-R 10$ & & & & & \\
\hline $\begin{array}{l}\text { yean } \\
\text { S. D. }\end{array}$ & $\begin{array}{l}0.09 \\
0.13\end{array}$ & $\begin{array}{l}0.39 \\
0.42\end{array}$ & $\begin{array}{l}0.62 \\
0.40\end{array}$ & $\begin{array}{l}0.85 \\
0.37\end{array}$ & $\begin{array}{l}0.96 \\
0.36\end{array}$ \\
\hline
\end{tabular}

DRO

$\begin{array}{llllll}\text { Hean } & 0.44 & 0.78 & 1.10 & 1.16 & 1.21 \\ \text { S.D. } & 0.20 & 0.31 & 0.22 & 0.18 & 0.27\end{array}$


Figure 8. Mean arcsin transformed total reinforcements per session for each of the three reinforcement-based response elimination procedures across the five sessions of the treatment phase. 
paqe 73

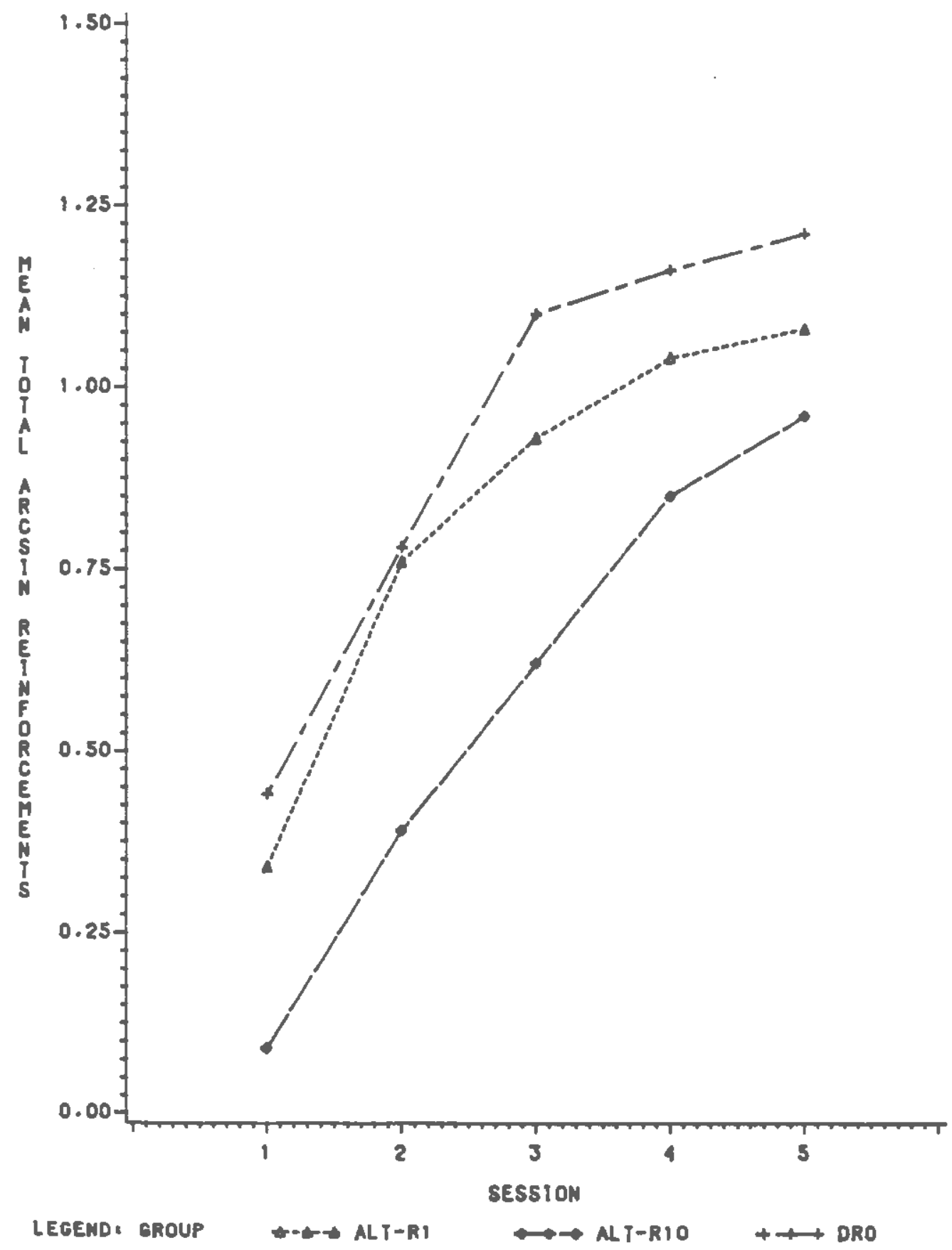




\section{Phase IV--Reacquisition}

Table 20 shows the means and standard deviations for reinforcements per minute for all groups across the 15 min of the reacquisition phase. The Hartley's test of homogeneity of variance for these data was again significant ( $\max (60,9)=35.66, p<.01)$. An arcsin transformation was performed on these data (after dividing each value by 6 , the total possible reinforcements per min, to create proportions), and the resulting weans and standard deviations are presented in Table 21. The Fmax value for these data was 15.90 ( $\underline{\underline{d}} \underline{f}=60,9)$. which vas nonsignificant. The mixed design analysis of variance summary table for arcsin transformed reinforcements per min for each group across the 15 mins of Phase IV is presented in Appendix I. The treatment effect was nonsignificant $(\underline{F}(3,36)=1.02)$. but both the time and time $x$ sessions effects vere significant at the $p<.001$ level $(\underline{F}(14,504)=29.36$ and $\underline{F}(42,504)=1.95$. respectively).

Simple effects tests were performed at each level of time in order to determine whether there were any significant differences in rate of reinforcement across groups. At minute 1, there vere no significant differences (F(3, 514) $<1.00)$, but at minutes 2 through 4 , the $\underline{F}$ values were significant at the $p<.01$ level, and at minute 4, there were significant differences at the $\mathrm{p}<.05$ level $\underline{F}(3,514)=8.70$ at minute $2: \underline{F}(3,514)=4.04$ at minute 
3; $\underline{F}(3,514)=3.00$ at minute 4$)$. From minutes 4 through 15. there were no other significant differences. At minutes 5 and 6 , the $\underline{F}$ values vere 1.89 and 1.98 respectively $(\underline{d} \underline{f}=$ 3. 514; p > .05). From minutes 7 through 15, the $\underline{\text { values }}$ were less than one, except that at both minutes 12 and 14 a value of 1.07 was obtained $(\underline{d \underline{f}}=3,514 ; \mathrm{p}>.05)$.

Newman-Kuels follow-up tests performed across groups at minutes 2 through 4 revealed a fairly consistent pattern of means. At minute 2, all groups were significantly different at the $p<.01$ level, except that the ALT-R1 vS. ALT-R10 comparison was significant at the $\mathrm{p}<.05$ level. At both minutes 3 and 4 , all groups were significantly different from one another at the $p<-01$, except that neither the EXT vS. DRO or the ALT-R1 vS. ALT-R10 comparisons vere significant.

The Omega squared values for this analysis vere .000 for treatments, .383 for time, and .033 for time $x$ treatments. As in previous reacquisition phase analyses, these results indicated that the interaction effect, which was of primary experimental interest, represented only $3.8 \%$ of the variance. 
Table 20

Heans and Standard Deviations for Total Reinforcements Per Session for Each Group Across the Fifteen Hinutes of the Reacquisition Phase

Group

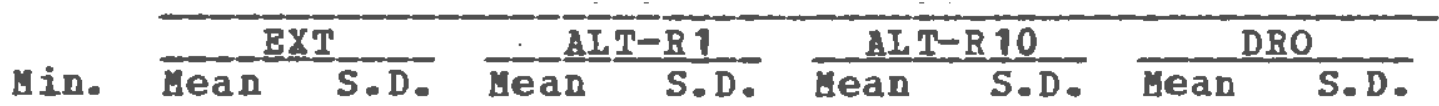

$\begin{array}{ccccccccc}1 & 0.70 & 1.64 & 2.00 & 1.82 & 1.90 & 1.97 & 1.00 & 1.15 \\ 2 & 1.10 & 1.66 & 3.60 & 1.90 & 4.30 & 1.77 & 2.00 & 2.16 \\ 3 & 2.10 & 2.51 & 4.70 & 0.95 & 4.20 & 1.81 & 2.40 & 2.06 \\ 4 & 2.60 & 2.46 & 5.00 & 0.47 & 4.50 & 1.71 & 3.20 & 2.25 \\ 5 & 3.70 & 2.11 & 5.10 & 0.74 & 4.50 & 1.78 & 3.40 & 2.41 \\ 6 & 4.40 & 2.01 & 5.30 & 0.48 & 4.80 & 1.81 & 3.80 & 1.81 \\ 7 & 4.80 & 1.55 & 5.10 & 0.57 & 4.60 & 1.78 & 4.50 & 1.78 \\ 9 & 4.70 & 1.89 & 5.10 & 0.74 & 4.60 & 1.78 & 4.50 & 1.27 \\ 10 & 5.00 & 1.82 & 4.70 & 0.67 & 4.90 & 1.79 & 4.90 & 1.66 \\ 11 & 5.20 & 1.03 & 5.30 & 0.67 & 5.00 & 1.82 & 4.70 & 1.42 \\ 12 & 5.50 & 0.71 & 5.30 & 0.48 & 4.60 & 1.71 & 5.00 & 1.15 \\ 13 & 5.20 & 0.79 & 5.60 & 0.52 & 5.00 & 1.88 & 5.20 & 1.23 \\ 14 & 5.80 & 0.42 & 5.20 & 0.92 & 5.10 & 1.85 & 5.10 & 0.99 \\ 15 & 5.00 & 0.94 & 5.40 & 0.52 & 4.80 & 1.75 & 4.90 & 0.88\end{array}$


Table 21

Heans and Standard Deviations for Arcsin

Transformed. Total Reinforcements per Minute_for_each

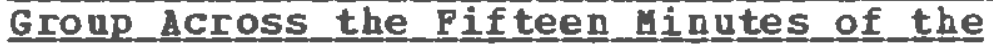
Reacquisition phase

\section{Group}

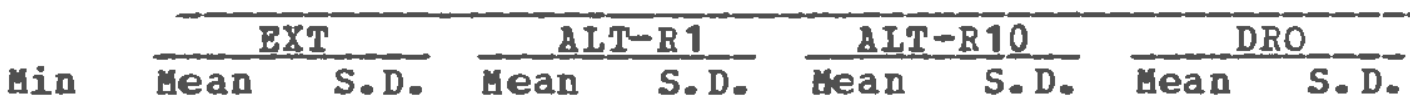

\begin{tabular}{|c|c|c|c|c|c|c|c|c|}
\hline 1 & 0.13 & 0.32 & 0.36 & 0.35 & 0.35 & 0.37 & 0.17 & 0.20 \\
\hline 2 & 0.20 & 0.30 & 0.76 & 0.52 & 0.91 & 0.46 & 0.41 & 0.51 \\
\hline 3 & 0.47 & 0.63 & 0.98 & 0.35 & 0.86 & 0.42 & 0.45 & 0.40 \\
\hline 4 & 0.54 & 0.56 & 1.02 & 0.21 & 0.95 & 0.44 & 0.65 & 0.51 \\
\hline 5 & 0.75 & 0.48 & 1.11 & 0.33 & 0.98 & 0.49 & 0.73 & 0.59 \\
\hline 6 & 1.00 & 0.57 & 1.16 & 0.28 & 1.09 & 0.50 & 0.73 & 0.37 \\
\hline 7 & 1.09 & 0.48 & 1.08 & 0.27 & 1.01 & 0.48 & 0.96 & 0.45 \\
\hline 8 & 1.07 & 0.52 & 1.11 & 0.33 & 1.01 & 0.48 & 0.88 & 0.26 \\
\hline 9 & 1.18 & 0.51 & 0.91 & 0.16 & 1.12 & 0.49 & 1.15 & 0.51 \\
\hline 10 & 1.14 & 0.45 & 1.28 & 0.38 & 1.09 & 0.50 & 1.12 & 0.49 \\
\hline 11 & 1.21 & 0.41 & 1.19 & 0.33 & 1.18 & 0.51 & 0.99 & 0.40 \\
\hline 12 & 1.31 & 0.34 & 1.16 & 0.28 & 0.98 & 0.44 & 1.10 & 0.38 \\
\hline 13 & 1.17 & 0.36 & 1. 34 & 0.30 & 1.21 & 0.54 & 1.21 & 0.42 \\
\hline 14 & 1.45 & 0.25 & 1.17 & 0.37 & 1.24 & 0.52 & 1.15 & 0.39 \\
\hline 15 & 1.09 & 0.36 & 1. 22 & 0.30 & 1.06 & 0.46 & 1.03 & 0.32 \\
\hline
\end{tabular}


Figure_9. Hean arcsin transformed reinforcements per minute for each group across the 15 mins of the reacquisition phase. 


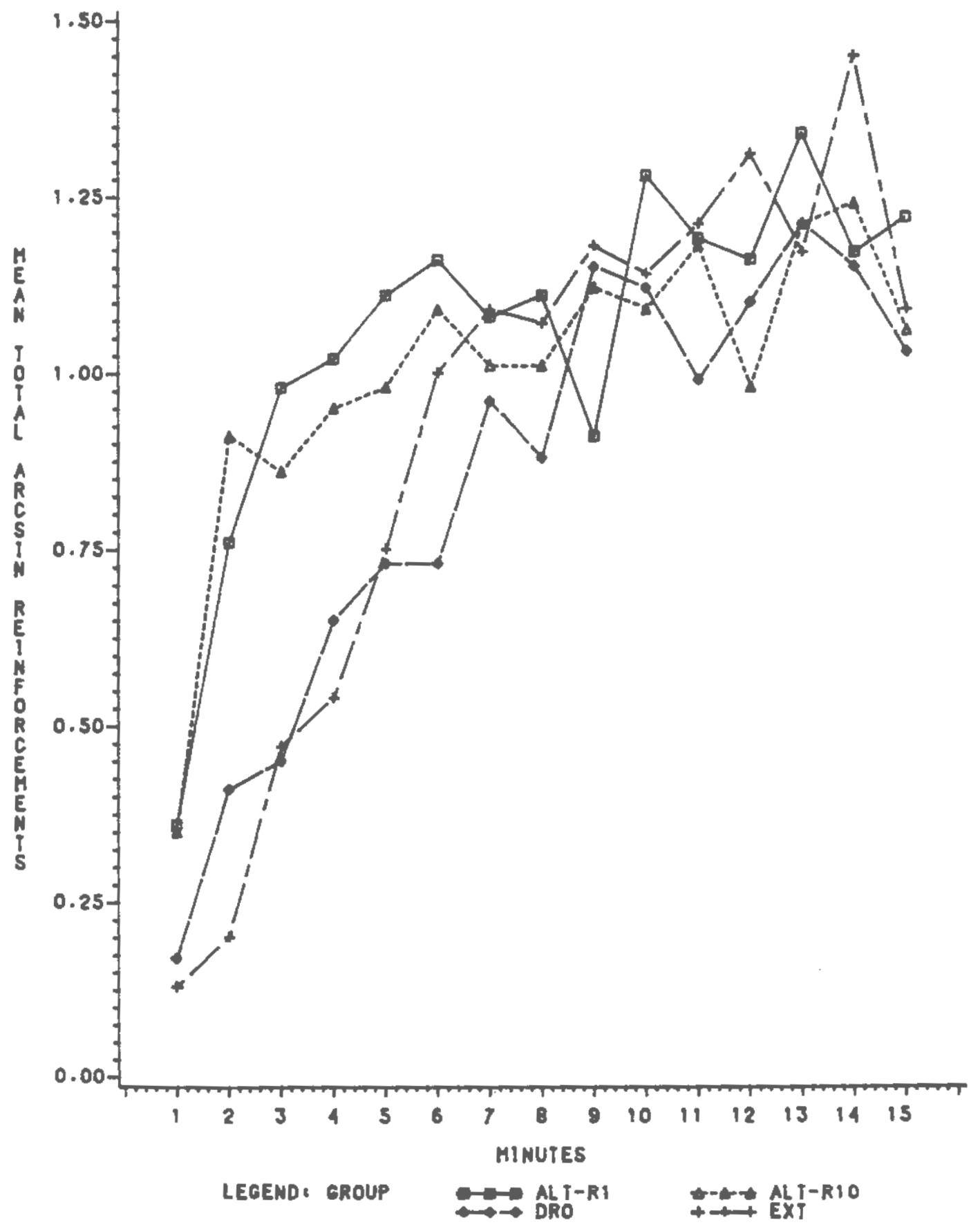




\section{Response Pattern Analysis}

The cumulative records presented in this section were selected on the basis of two criteria: 1) the representativeness of the curves of these records relative to others under the same experimental conditions and 2) the number of original lever responses shown. In each case the total original responses for each cumulative record shown in this section is less than .5 standard deviations from the mean of the cell from which it is drawn.

Records a. and b. in Pigure 10 show typical response patterns at the end of Phase $I$. The upper line represents cumulative original lever responses over time, and should be interpreted by its relative slope. A steeper slope represents a higher rate of responding. while a shallower slope represents a lower rate. Each downward slash of this line indicates the delivery of a reinforcement. The lower line is an event record of responses on the alternate lever. Records a. and b. show a steady, moderate rate of responding on the original lever and little or no responding on the alternate lever. The records show little of the scalloping effect characteristic of fixed-interval schedules, perhaps due to the very brief 10-sec interval and the fact that by this point optimal performance had not been reached, as indicated by the increasing means for original lever responses in Table 1. 
Records c. through f. show curves produced on the first session of each treatment condition. Record c. shows the EXT condition and a typical extinction curve (Skinner, 1938) with a relatively high rate of unceinforced responding early in the session, gradually tapering of to a much lower rate near the end of the session.

Record d. shows the initial session of an ALT-R1 subject. Early in the session the curve is very similar to the extinction curve in c.. but after approximately five minutes of the session had passed, an alternate lever response is made and reinforced and responding soon switches to that nipulanda (as indicated by the increasing density of slash marks on the lower line). This switch to the alternate lever produces a flatter top to the original lever curve than the extinction curve in $c$.

Record e. in Figure 11 shows the initial treatment session of an ALT-R10 subject. It appears very similar to the ALT-R1 subject of d.. except that the switch to the alternate lever occurs later in the session. This was a fairly typical effect of the 10-sec COD. As can be seen in e.. the first two responses on the alternate lever went unreinforced because the 10 -sec changeover requirement had not been met. This is in contrast to $d_{\text {... where the initial }}$ alternate lever responses were reinforced.

Record f. shows the initial Phase II session of a DRO subject. Here there was little increase in alternate lever 
responses (as reflected by the few slashes on the lower line). but as the subject paused during runs of responses on the original lever, the $10 \mathrm{sec}$ response-reinforcement interval was met and reinforcement was delivered (shown by slash marks on the upper line). Since the DRO contingency required a lack of responding on the original lever to obtain reinforcement, slashes on the upper line only occur after flat spaces of no responding.

Records g. through h. show response patterns for subjects in the last session of Phase II. Here each treatment condition has been in effect for five sessions. and the cumulative records show very low levels of original lever responses. In $g$. the EXT subject shows the shallow curve typical of the later stages of extinction (Skinner, 1938). Records h. and i. (ALT-RI and ALT-R10 respectively) show relatively high, steady rates of responding on the alternate lever, and a regular rate of reinforcement. Both show very low rates of original lever responses with slightly fewer responses for the ALT-R10 subject. Finally, in j. a typical DRO subject shows very low levels of both original and alternate lever responses and a steady pattern of reinforcement. Here, too, the rate of original lever responses is less than in either the EXT or ALT-R1 subjects.

Figure 12 shows typical cumulative records for each group during the first session of the extinction condition. 
Phase III. Record $k$. shows an EXT subject continuing to extinguish to lower levels of original lever responses. In 1. through n.. the subjects from the three reinforcement-based procedures responded for the first time under conditions in which no reinforcement was available at a11. and in each case the rates of original lever responses were much higher than at the end of the treatment phase (see Figure 11. g. through j.). Both the ALT-R1 (1.) and ALT-R10 (m.) subjects showed high rates of alternate lever responding, but in this case the pattern is less consistent. reflecting much shifting back and forth between the two levers. In the ALT-R10 subject, changeovers between levers appear to have been less frequent, but in both cases runs of responding on the alternate lever vere often followed by bursts on the original lever. The DRO subject shows a fairly typical, though more shallow extinction curve with a few bursts on the alternative lever. As in the previous two cumulative records, there is a significant rebound in original lever responding compared to levels produced at the end of Phase II (see Figure 11, record i.).

Figure 13 shows representative cumulative records for subjects from each treatment group during the reacquisition session, Phase IV. In this case, records were selected on the basis of their closeness to mean rates of original lever responding in minute 3 of Phase IV. since this was the first minute in which significant differences between groups vere 
found. The curves are remarkable in that, with the possible

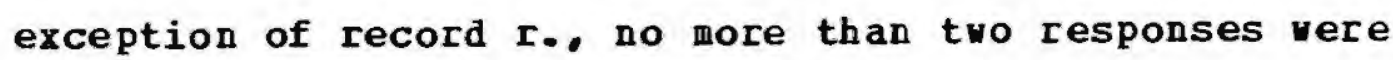
required before very steady rates of original lever responding were regained at levels almost identical to those seen at the end of the training phase (see Figure 10. records a. and b.l. This pattern is consistent with the immediate reconditioning after extinction reported by Skinner (1938). In the ALT-R1 (p.) and ALT-R10 (q.) subjects, reacquisition occurred after a single response. For the EXT subject, reacquisition was complete after the second response, but in this case the first response was not made until over a minute into the session, and then the second response occurred approximately a minute after the first. This pattern suggests that the statistically significant lower levels of responding in the EXT group during the early minutes of Phase IV reflect the very low levels of responding produced by this group after 10 sessions of extinction. As shown in the statistical analysis of Phase III, all three of the reinforcement-based procedures showed significantly higher rates of original lever responses at the end of the extincition phase. Finally, record $r$. (DRO) is of particular interest because it shows a more gradual rate of reacquisition. original lever responses were made at the beginning of the session, but in this case the rate of response showed a slightly more gradual reacquisition, as characterized by a steepening 
curve at the beginning of the session. Jnlike the other three subjects whose former rates vere regained almost

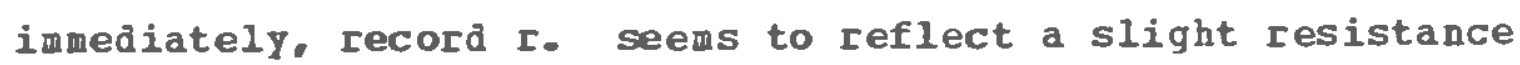
to reacquisition in the early minutes of the session. 
Piqure 10. Cumulative records of subjects in Phases I and II. Records $a$. and b. show typical subjects during the final session of the training phase. Record c. shous an EXT subject during the first session of the treatment phase, and record d. is of an ALT-R1 subject also in the first session of the treatment phase. 


$$
\frac{y y}{2 y}
$$


Pigure 11. Records $e$. and f. Shoy ALT-R10 and DRO subjects, respectively, during the first session of Phase II. Records g. through j. are example cumulative records of subjects from each of the treatment groups during the last session of the treatment phase. Record $\mathrm{g}$. is an EXT subject, record h. is an ALT-R1 subject, record $i$. is an ALT-R10 subject, and record $j$. is a DRO subject. 

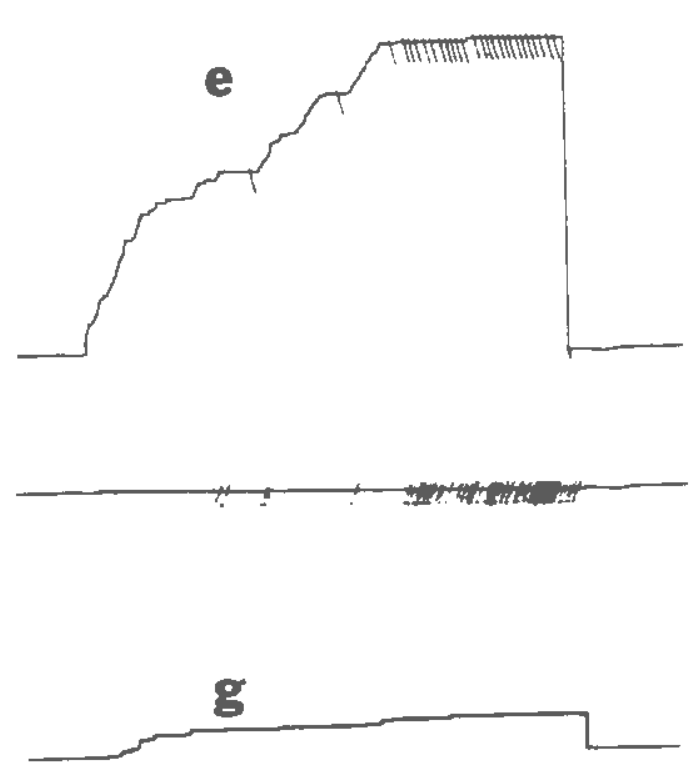

i

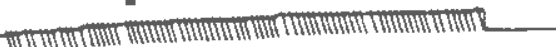

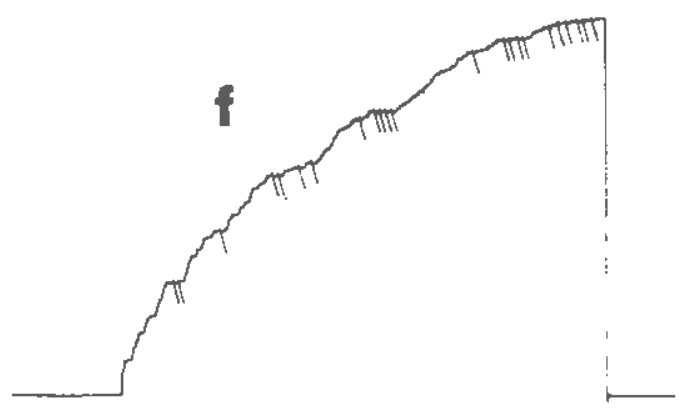

h

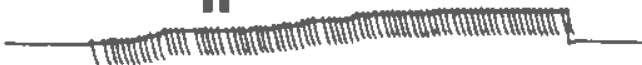
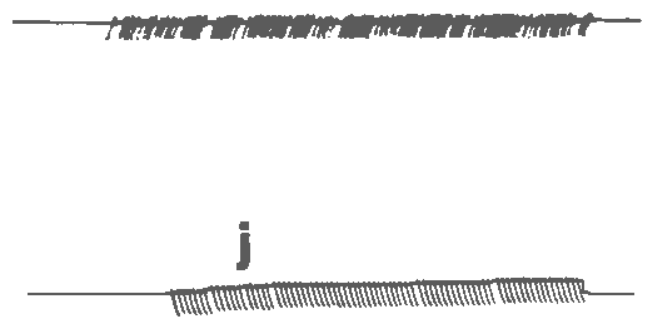
Figure 12. Representative cumulative records of subjects from each treatment group during the first session of the extinction phase. Record $k$. is an EXT subject. record 1. is an ALT-R1 subject, record $m$. is an ALT-R10 subject, and record $n$. is a DRo subject. 

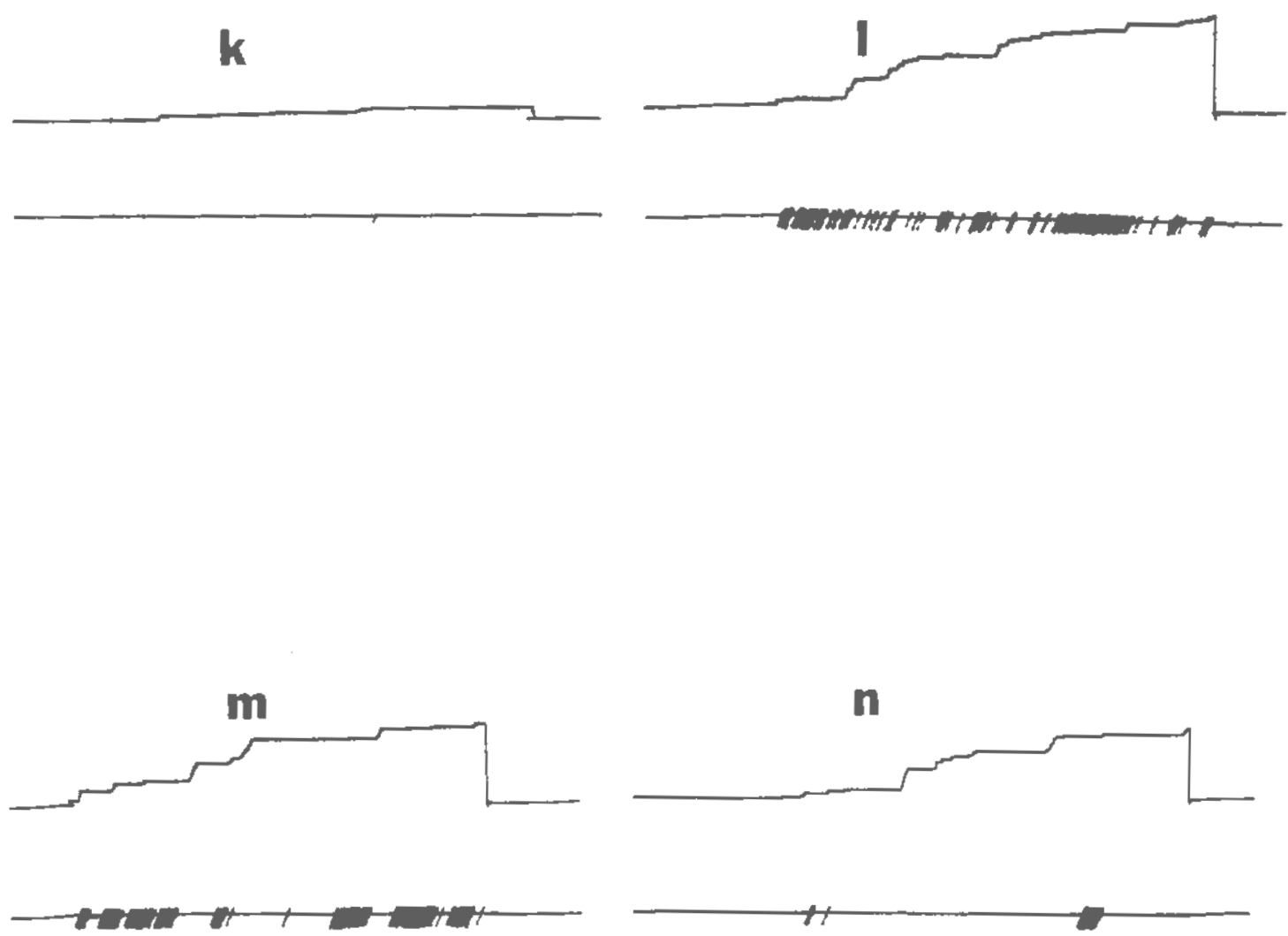
Fiqure 13. Representative cumulative records of subjects from each treatment group during the reacquisition phase. Record o. is an EXT subject, record p. is an ALT-R1 subject, record $\mathrm{G}$. is an ALT-R10 subject, and record I. is a DBO subject. 


$$
\frac{1 y}{1 y}
$$




\section{Discussion}

This research has produced a number of noteworthy results. One of the most interesting of these is the effectiveness of the ALT-R 10 procedure in Phase II. DRO controlled a consistently low rate of responding in the last three sessions of this condition. but in sessions three and four ALT-R10 was equally effective and in session five was even more effective. It is surprising that ALT-R1 produced consistently higher rates of responding in light of previous research showing a quicker initial treatment effect for ALT-R1 than for DRO (Uulick \& Leitenberg, 1978; Hulick, et al.. 1976). The DRO and $A L T-R 10$ groups were the two reinforcement-based groups for which a specific contingency was programmed for responses on the original lever (other than the brief $1 \mathrm{sec} C O D$ for $A L T-R 1)$, and the results of Phase II suggest that this aspect of these contingencies had an important effect. Particulary striking is the comparison between ALT-R1 and ALT-R10. These two procedures were exactly the same, except that the COD for the ALT-R10 group was extended to 10 sec, providing a longer penalty (in the form of an interruption in the schedule of reinforcement on the alternate lever) for responses on the original lever. Nevertheless, as Figure 2 shows, this relatively subtle 
difference in the contingencies produced a reliably lower rate of responding for ALT-R10 at sessions three through five. That this additional penalty had a bearing on the results for this phase is confirmed by the reinforcement rate analysis, which indicated a lower rate of reinforcement for ALT-R10 across all levels of sessions (see Pigure 8). The analysis of rebound effects during Phase III follows very closely the effects of phase II. First, a significant rebound was shown for all reinforcement-based procedures, and this effect was reflected in rates of original lever responding which vere much greater than the EXT group at all levels of sessions. This result is consistent with the majority of previous studies (e.g. Leitenberg, et al.. 1975: Pacitti \& Smith, 1977) except that in this case the rebound was maintained across more sessions, possibly due to the fixed-interval training schedule in combination with a relatively short (15 min.) session length in this research. of greater experimental interest is the superiority of $A L T-R 10$ and DRO over ALT-R1. Here, as in phase II, the two reinforcment-based procedures involving a penalty for original lever responses controlled lover rates of responding than ALT-R1 in sessions three through five. There was no significant difference between these two procedures except that in the initial session of the extinction phase ALT-R10 produced fewer original lever responses than either ALT-R1 or DRO. As in the previous 
phase this result confirms the greater response elimination effect of ALT-R10 and DRO, and suggests that, at least under treatment and extinction conditions, the ALT-R10 procedure is slightly more effective than DRO. (This conclusion is based on the results of Phase II session five and Phase III session one.)

The results in Phase IV were somewhat different from previous conditions. In the reacquisition phase, differences between groups were transitory, appearing only in minutes 2, 3, and 4, but for this brief period the superiority of the DRO procedure was clearly demonstrated. Subjects in the EXT group, as discussed in the response pattern analysis, had reached a very loy rate of responding by the end of Phase III (a mean of 4.20 responses per session by session 5 ) and reacquired the original lever response slower than subjects in any other group. Nevertheless, DRO subjects showed a consistently lover rate of responding than subjects under either of the other reinforcement-based procedures in minutes 2 through 4 . This result is consistent with pacitti and Smith (1977) who found DRO subjects more resistant to reacquisition than those under two counter conditioning procedures similar to the present ALT-R1.

The number of original lever responses for ALT-R1 and ALT-R10 vere significantly different in minutes 2 through 4. but because ALT-R10 shoved a higher rate at minute 2 and 
ALT-R 1 showed higher rates at minutes 3 and 4 , no consistent difference between the two was produced. Nevertheless, the alternate lever analysis for this phase suggests an explanation for this pattern of results. As Figure 7 indicates, the ALT-R1 group began Phase IV with a high rate of alternate lever responses which showed a steady and rapid decline through minute 5. In contrast, ALT-B10 began the session with a relatively low rate of alternate lever responses which showed a gradual increase to a peak at minute 5 and 6 before decreasing again through minute 9. While ALT-R1 and ALT-R10 showed no significant differences in rate of alternate lever responses at minutes 3 and 4 . ALT-R 1 did show a significantly higher rate at minute 2 , the point at which that group showed a lower rate of original lever responses than ALT-B10.

The relatively late burst of alternate lever responding in the AIT-R 10 group produces another important difference between this response elimination procedure and any of the others examined in this study. While the original lever analysis in Phase IV produced no significant differences beyond minute 4 , at minutes 5 through 7 , ALT-R10 controlled a significantly higher rate of alternate lever responding than any other group. As a result. this group produced more lever responses in general (including both original and alternate lever responses) than any other group during the period of minutes 2 through 7 . Once again the relatively 
subtle difference between ALT-R1 and ALT-R10 (a $10 \mathrm{sec}$ COD) has produced a surprisingly dramatic difference in effects. This collection of results suggests a number of conclusions. Perhaps the most important is the superiority of DRO as a response elimination procedure. It produced rates of responding almost as low as any other response elimination procedure during Phases II and III and shoved slower reacquisition in Phase IV. This resistance to reacquisition is of particular interest because it reveals a functional difference between DRO and DRI (DRI here is used in either its more common sense (Hoods, 1982, similar to the present ALT-B1) or in the sense of Tarpley $\&$ Schroeder (1979) which is similar, though not exactly comparable, to the present ALT-R 10). Woods (1982) has suggested that there is no difference between the two contingencies, arguing that research in superstitious and schedule-induced behavior indicates that specific incompatible responses are conditioned in DRO. However the equivalence of these two contingencies is an empirical question, and the results of Phase IV show a clear point of separation. While the ALT-R10 and DRO groups vere nearly equivalent through the treatment and extinction conditions, the DRO group shoved significantly slower reacquisition.

A possible explanation for this slower reacquisition is the essential difference between this contingency and the others examined here. The only requirement for 
reinforcement under the DRO condition was the nonoccurrence of an original lever response for a $10 \mathrm{sec}$ period. All other behavior was reinforced. While superstitious and schedule induced responses might be expected to develop. random variations in these responses, which would also be reinforced (provided they did not involve original lever responses), make this contigency different from DRI (ALT-R1 and ALT-R10). A number of responses are reinforced, while only one is not. In the FI training condition and in both the ALT-R 1 and ALT-R 10 treatment conditions only specific responses were reinforced. While other research has shown that the topography of the response has little bearing on ALT-R's effectiveness (Leitenberg et al.. 1975: Pacitti \& Smith, 1977), the present study and others (Pacitti \& Smith, 1977) suggest that the single response (ALT-R) vs. any response but a single response (DRO) distinction between these contingencies can have an important impact.

A second major finding of this research is that, as in previous studies (Leitenberg, et al.. 1975). none of the reinforcement-based procedures resulted in a "savings" of total original lever responses when both treatment and extinction phases were combined. This result is consistent with the Estes (1944) theory of punishment; however, as discussed above, this theory is no longer widely accepted (Azrin \& Holz, 1966). Furthermore, the results of the "savings" analysis appear to depend upon a number of 
conditions, such as session length and the number of sessions run in both the treatment and extinction phases. In the present study, no attempt was made to extend either Phase II or III until subjects in any or all groups vere completely extinguished.

Final1y, the finding of greatest experimental interest was the effect of the lengthened COD on the performance of the ALT-R10 group. While Catania (1966) showed the dramatic effects the addition of a COD can have on concurrent schedules, the present study established that this effect can be maintained after the schedule has been switched from conc FI 10-sec EXT to conc EXT EXT. This was reflected in the data for the ALT-R10 group, where the additional requirement of a $10 \mathrm{sec}$ period free of original responses had an important effect in Phases II and III.

\section{A Fey Hords_About Terminology}

The present study has maintained the use of the term alternate reinforcement (ALT-RI and ALT-R10) because it is firmly connected with this line of response elimination research. However, in the interest of accuracy, a more general description of the various contingencies might have been more useful. Translation into the more widely used language is easily accomplished.

In the case of the EXT group, the terminology is straightforward. For purposes of experimental interest, 
responses on both manipulanda were measured, but the lack of any reinforcement history on the alternate lever exposes the EXT group to a simple FI 10-sec schedule in Phases I and IV and an extinction schedule in phases II and III.

While it might be argued that DRO is a concurrent schedule in wich the second response is reinforced but not measured, this research and current usage would present it as a single operant contingency. As a result the DRO group was exposed to FI 10-sec in Phases I and IV, DRO 10-sec in Phase II, and extinction in Phase III.

The addition of an FI 10-sec schedule of reinforcement on the alternate lever for the ALT-R1 and ALT-R10 groups makes these concurrent schedules from Phase II through Phase IV. The groups were exposed to a sinple FI 10-sec schedule in Phase I, a çong FI 10-sec EXT schedule in Phase II, a Conc EXT EXT schedule in Phase III, and a conc EXT FI 10-sec schedule in phase IV. The essential difference between the two schedules is the length of the COD.

\section{Aternate_Reinforcement and the uatching lay}

The plethora of current research on, or influenced by. the matching law (Herrastein, 1961) all but obligates the discussion of its relation to any study involving concurrent operants. In his initial investigation, Herrnstein (1961) found that the number of responses a subject makes on one of two concurrent schedules can be accurately predicted from 
the number of responses made on the other schedule and the relative rate of reinforcement available on each schedule. The specific mathematical formulation is:

$$
\frac{\mathrm{R} 1}{\mathrm{R} 1+\mathrm{R} 2}=\frac{\mathrm{r} 1}{\mathrm{r} 1+\mathrm{r} 2}
$$

Here $R 1$ and $R 2$ represent the frequency of response on each schedule and $I 1$ and $I 2$ represent the rate of reinforcement on each schedule. It has also been shown (de Villiers, 1977) that the amount of time spent responding on each schedule can be predicted by this formula and that the relative delay of reinforcement or amount of reinforcement can be used as predictors. A wide variety of factors can affect the accuracy of this formula (producing "undermatching" or "overmatching"), but under a number of conditions it produces accurate predictions (de villiers, 1977) .

However, the matching law applies only to concurrent schedules wich have been brought to optimal, steady-state performance and has fostered a "molar" approach to behavior. which is concerned with the mathematical description of steady-state behavior (Catania, 1979). This new perspective has been lamented by those vho promote a more "molecular" analysis of patterns of responding, both early and late in the conditioning process (Uichael, 1979; Skinner, 1976). The present study is in the molecular tradition. In 
its simplest form, the matching law would make no differential prediction of relative response rates for either the ALT-R1 or ALT-B10 groups. While the length of COD has been identified as an important determinant of the accuracy of predictions based on the matching lav (de villiers, 1977), the applied goals of this study demanded a more molecular examination. Response elimination procedures similar to those studied in this research are often applied to human behaviors which have serious personal and social conseguences (e.g. self-injurious or aggressive behavior in mentally retarded clients). Given this type of application. research in response elimination should be concerned with rates of response at all stages in the conditioning process. As a result, a session-by-session and moment-by-moment analysis was appropriate for the current research.

\section{Some Applied Implications of this Research}

There are two major results of this study which may have siqnificance for applied psychology. First, the effectireness of $\mathrm{DRO}$ as a reponse elimination procedure was demonstrated in Phases II and IV. Particularly noteworthy vas the DRO group's slover reacquisition of the original response in Phase IV. These results suggest that DRO should be an effective response elimination procedure for applied use. Interestingly, while DRO is videly used, the majority of applied research studies examining this contingency have 
employed it in combination with with other procedures, such as time out (Woods, 1983). This suggests that DRO's effectiveness in animal studies may be due, in part, to peculiarities of the laboratory which are not characteristic of applied settings. In addition, Lindsley (personal conmuication, November 7, 1983) has argued against applications of DRO on the grounds that it does not develop new behavior. He suggests that behavior analysts apply the "dead man test," which holds that, if a dead man could receive reinforcement under the designed contingency, then it cannot be reinforcing new behavior. While Iindsley's objection to DRO appears to be based primarily on professional and ethical concerns for the careful choice of applied interventions, it is a viev shared by many applied psychologists (Deitz \& Repp, 1983).

The second finding of importance for the clinical use of response elimination procedures yas the effectiveness of the ALT-R 10 procedure in Phase II. Its superiority to DRO in session five and to $A L T-R 1$ in sessions three through fire have raluable implications for the application of DRI procedures. This research suggests that response elimination procedures which combine reinforcement of an incompatable response with a response-reinforcement interval (like DRO) may prove to be equal to or more effective than DRI or DRO alone. Such a procedure yould be similar to, thongh not exactly comparable with, the DRI procedure used 
by Schroeder and Tarpley (1979). Finally, while ALT-R10 showed more rapid reacquisition than DRO in Phase IV, it may be more palatable for clinicians since it allows for the choice of incompatable behaviors which have educational or adaptive value.

\section{Limits to the Applied Implications of this Research}

While the stated goals of this research included the hope that it would add to a body of knowledge which might lead to more effective treatment of behavioral excesses in human beings, there are a number of issues which limit its applied significance.

First and perhaps most obviously, this is animal research which cannot be easily applied to humans. Research on fixed interval responding in humans (Poppen, 1982) has indicated that, while these schedules show a consistent scalloped pattern in a wide variety of animal species, human subjects with well developed verbal repertoires rarely show the familiar scalloped pattern. As a result, the contingencies studied here may have more relevance for the severly and profoundly mentally retarded and other non-verbal populations than for verbal subjects.

A second limitation is created by differences between response elimination reinforcement contingencies as they have been studied here and as they are likely to be encountered in applied settings. In this study the original 
response was trained under an FI 10-sec schedule in Phase I and was switched to EXT in the treatment and extinction phases. This is a hypothetical and questionably valid course of contingencies in natural settings. In many cases the contingencies of reinforcement which support an undesirable behavior are unknown to the clinician. In addition, even if the majority of reinforcement for a response is eliminated through differential reinforcement procedures, the multiple sources of reinforcement in natural settings make it probable that reinforcement will still be available for the target response on some unknown schedule.

If we abbreviate the unknown contingencies of reinforcement as oc1 (during original training. or pre-treatment) and UC2 (during treatment) a more accurate scheme of the applied contingencies can be described. (Note: in some situations UC1 might equal oC2, but advances in behavior analysis make it likely that they will not.) The majority of applied behavioral treatments involve both procedures for obtaining reinforcement for incompatable behavior and efforts aimed at the limiting of reinforcement obtained through the undesired response. Onder this arrangement Phase I for all treatment conditions would be a simple UC1 schedule. In the DRO condition. Phase II would involve a conjoint schedule (coni DRO OC2) in which both schedules operate simultaneously on the same manipulanda. This is similar to the conjoint DRO schedules studied by 
Zeiler (1976; 1977). For both ALT-R1 groups, the present terminology would produce a conc ALT-R UC2 schedule in phase II rather than the present conc ALT-B EXT. Finally, the present analysis of the original response makes the EXT group in this study of questionable value as a control condition. In addition, if the EXT group is not a valid control. then Phase III and the "savings" analysis are also tests of questionable relevance to the probable applications of these contingencies in natural settings.

Finally, a third limitation to the applied significance of this research is concerned with the relative effort of responses in natural settings. The relative effort of a response is a variable which can have important effects on response rate (Chung, 1965) and intensity (skinner, 1938). However, effort is rarely studied in the laboratory and. perhaps as a result, does not play a prominent part in many theories of learning. Nevertheless, it should play an important part in the analysis of concurrent operants in both experimental and applied contexts.

The study of concurrent operants in the laboratory has almost without exception involved responses of equal effort, either because a single manipulanda was used in conjunction with a changeover key or because two identical keys or levers were used. Yet chung's (1965) study of single and concurrent operants showed that, when the effort requirements were increased, response rates decreased. 
Therefore, the effort involved in each response is an important consideration in the study of concurrent operants. In addition, effort seems to be important in changeover behavior. While this aspect of effort has been studied infrequently (various schedules of fixed ratio cods--which could be interpreted as requiring varying amounts of effort--have been studied (Plisk off \& Fetterman, 1981)), it is a relevant factor for concurrent operants. The effort of changeovers can be varied through fixed ratio coDs (requiring a number of consecutive responses on the new manipulanda before its schedule goes into effect). manipulating the force requirement on the changeover key, or by moving the manipulanda apart. If, as in the present study, the manipulanda are physically separated, two effects result: (a) the effort requirement for changeovers increases as a function of the animal's weight and the distance between the two operants and (b) a COD is created by the time delay inherent in travelling from one manipulanda to another. Experimentally, the effort of changeovers and length of COD could be varied independently using the single key procedure by controlling the effort on the changeover key and the length of the COD, but when the distance betveen manipulanda is varied a positive, dependent relationship exists between COD length and effort. Greater distance creates longer CODs and greater effort.

While these issues are not widely discussed in basic 
research on concurrent operants, their importance becomes obvious when placed in a real world context. In natural settings, organisms are confronted with gany concurrent operants; however, they rarely involve equal effort. In addition. "changeover" force requirements and coDs can vary. Deitz and Repp (1983) have used the terms DRI, for differential reinforcement of incompatible responses (meaning, in this case, phrsically incompatable), DRA, for differential reinforcement of alternate behavior uhich is not incompatable (similar to the $\mathrm{ALT}-\mathrm{R}$ of basic research literature (Leitenberg et al., 1970)/, and have argued for the superiority of DRI without providing adequate analysis of the functional relationship between two. However, in light of the forgoing discussion of effort and concurrent operants a plausible interpretation can be presented using existing terminology.

The difference between DRA and DRI appears to be analogous to moving the manipulanda farther apart. If two responses are physically incompatible, changing over from one to the other is affected by both increased effort and increased delay of reinforcement. whereas in the DRA procedure, both operants are simultaneously available and, the only variables affecting response rate are the effort and schedules of reinforcement for each operant. The present research has shown in an animal experiment that given two physical1y incompatible responses in a context 
similar to DRI (ALT-R1 and ALT-R10) the addition of a long coD can significantly increase response elimination effects.

\section{Conclusions}

This research has made two contributions to our knowledge of response elimination contingencies. The first of these concerns the length of COD employed in the ALT-R treatment condition. The longer COD of the ALT-R10 group produced significantly fewer original lever responses than the ALT-R1 group in three sessions of Phase II and all five sessions of Phase III. These results indicate that the greater delay to reinforcement correlated with responding on the original lever for the ALT-R 10 group had a significant effect both during the treatment phase and after reinforcement was no longer available for any response. This consistent superiority of the ALT-R10 group did not hold in Phase IV where the reacquisition curves for each group were essentially the same. An important suggestion of these effects is that the results of previous studies, in which a variety of COD lengths have been used, may have been influenced by this variable. The extent to which coD can influence conclusions about the ALT-R procedure was dramatized by the finding that a 1 sec COD produced a treatment which was consistently less ef fective than DRO, yet a $10 \mathrm{sec} C O D$ produced a treatment which was marginally more effective than DRO. 
The second contribution of this research is concerned with the relative effectiveness of DRO and ALT-R10. Consistant with previous research (Pacitti $\varepsilon$ Smith, 1977). the DRO group was extremely effective. Of the 11 points at which significant differences were found, DRO was only surpassed by a reinforcement-based procedure twice. This groups slower reacquisition of the original response in Phase IV was particularly noteworthy and, as discussed above, may have been due to the essential nonresponse contingency of this procedure.

In comparison, the ALT-B10 procedure was either superior to or not significantly different from DRO through Phases II and II, indicating that the ALT-R procedure combined with a DRO-like response-reinforcement interval results in a response elimination procedure which is more effective than either ALT-R without the COD or DRO alone. The exception to this pattern came in Phase $I \nabla$, where ALT-R10 showed more rapid recovery of the original response than DRO.

Finally, the conclusions to be drawn from these major findings can be briefly summarized in two concise statements. First, since the essential difference between the ALT-R1 and ALT-R10 contingencies was the length of COD, the present research has demonstrated that, while this distinction is of importance under conditions of treatment and extinction, it is less important in reacquisition. 
Second, since the essential difference between DRO and ALT-R 10 was that in one condition reinforcement was arailable for any behavior other than the original response and in the other reinforcement was only arailable for the alternate response, this distinction was shown to be of marginal importance under treatment and extinction conditions, but of greater importance in reacquisition. Taken together, these results and conclusions suggest that the present research has summarized the functional effects of the two characteristics which separate the ALT-R and DRO contingencies: 1) the single alternate response versus any response other than the original response distinction and 2) the presence or absence of a response-reinforcement penalty for original responses.

In addition to these experinental findings, the present research has given strong evidence for the efficacy of applied response elimination procedures which combine differential reinforcement for responses which are incompatable with the target behavior (DRI) with a response-reinforcement delay interval contingent upon occurrence of the target beharior (similar to DRO). Such a contingency appears to control low rates of responding similar to those associated with DRO, yet it allows for the building of alternate, desirable behavior. While a numer of factors impede the easy extrapolation from laboratory research with other species to clinical use with humans. 
historically, the development of behavior modification techniques for the reduction of behavioral excesses has been tied to earlier animal research in punishment and reinforcement-based response elimination (Reese, 1978). As a result, behavioral treatments based on the findings reported here may lead to useful applications in a variety of field settings. 
References

Azrin, N.H. $\varepsilon$ Holz, H.C. Punishment. (1966). In W.K. Honig (Ed.), Operant Behavior:_Areas_of research_and. application. New York: Appleton-Century-crofts. Boe, E.E. (1964). Extinction as a function of intensity of punishment, amount of training, and reinforcement of competing response. Canadian Journal of psychology. 18 , 328-345.

Boneau, C. A. (1960). The effects of violations of assumptions underlying the test. psychological Bulletin, 57, 49-64.

Brulle, L.E. (1983) - Aversive techniques and the doctrine of least restrictive alternative. Exceptional Education Quarterly. $3,1-8$.

Catania, A.C. (1966). Concurrent operants. In W.K. Honig (Ed.), operant behavior: Areas of research and application. New York: Appleton-Century-Crofts. Catania, A.C. (1979). Learning. Englewood Cliffs, New Jersey: Prentice Hall, Inc. Cohen, J.I. (1981). Inferential_statistics. Champaign. Illinois: Dniversity of Illinois. Chung, S. (1965) - Effects of effort on response rate. Journal of the Experimental Analysis of Behavior. 8 . 1-7. 
Deitz, E.D. E Repp, A.C. (1983) - Reducing behavior

through reinforcement. Exceptional Education. Quarter1y. 3. 34-46.

Deitz, S.M. (1978). Current status of applied behavior analysis: Science versus technology. American Psychologist. 33. 805-814.

de villiers, P. (1977). Choice in concurrent schedules and a quantitative formulation of the lay of effect. In W.K. Honig \& J.E.R. Staddon, Handbook of Operant Behavior. Englewood cliffs, New Jersey: Prentice-Hall, Inc. Enkema, S., Slavin, R.. Spaeth, C., E Neuringer, A. (1972). Extinction in the presence of free food. Psychonomic. Science. 26, 267-269.

Epling, H.F. E Pierce, У.D. (1983) . Applied behavior analysis: New direction from the laboratory. The Behavior Analyst, $6.27-37$.

Epstein. R. (in press). Resurgence of previously reinforced behavior during extinction. Behaviour. Analysis_letters.

Epstein, B. E Medalie, S.D. (1983). The spontaneous use of a tool by a pigeon. Behaviour Analysis Letters. 3 . 241-247.

Estes, W.K. (1944). An experimental study of punishment. Psychological Honograph. 57 (3, Whole No. 263). Glass, G. Peckham, P., \& Sanders, J. (1972). Consequences 
of failure to meet assumptions underlying the fixed effects analysis of variance and covariance. Review_of Educational Research, 42, 237-288. Herrnstein. R.J. (1961). Relative and absolute strength of response as a function of frequency of reinforcement. Journal of the Experimental Analysis of Behavior. 4 , 267-272.

Johnson, D.I., McGlynn, F.D.. E Topping, J.S. (1973). The relative efficiency of four response-elimination techniques following variable-ratio reinforcement training. The Psychological Record, 23. 203-208. Leitenberg, H., Rawson, R.A., E Bath, K. (1970) .

Reinforcement of competing behavior during extinction. Science, 169, 301-303.

Uulick, J.A. (1975). Use of positive reinforcement contingencies to suppress behavior during extinction. (Doctoral dissertation, Oniversity of Vermont, 1975.) Dissertation_ Abstracts International, 36, $3095 \mathrm{~B}$. แulick, J.A. E Leitenberg, H. (1978, March). Extinction. omission, and alternate response training: The effects of cues associated with the reinforcing event. Paper presented at the $49 \mathrm{th}$ annual meeting of the Eastern Psychological Association, Washington, D.C. Leitenberg. H., Rawson, R.A.. E vulick, J.A. (1975). Extinction and reinforcement of alternative behavior. Journal of Comparative and Physiological Psychology, 
88. 640-652.

Lovaas, O.I. $\varepsilon$ Simmons, J.Q. (1969). Manipulation of self-destruction in three retarded children. Journal of Applied Behavior Analysis. 2. 143-157.

Lowry. H.A. E Lachter, G.D. (1977). Besponse elimination:

A comparison of four procedures. Learning_and otivation, ㅇ, 69-76.

Martin, R. (1975). Legal challenges to behavior

modification: Trends in schools, corrections, and

mental health. Champaign, Illinois: Research Press. Michael, J.L. (1979). Reinforcement magnitude and the inhibiting effect of reinforcement. Journal of thene. Experimenta1 Analysis of Behavior, 32, 265-268. Michael, J.L. (1980). Flight from behavior analysis. The Behavior Analyst. $3,1-21$. Bulick, J.A.. Leitenberg, H., E Rawson, R. A. (1976). Alternate response training, differential reinforcement of other behavior, and extinction in squirrel monkeys (Saimiri Sciureus) - Journal of the Experimental Analysis of Behayion. 25, 311-320. Mulick, J.A., Schroeder, S.R.. \& Rojahn, J. (1980). Chronic ruminative vomiting: A comparison of four treatment procedures. Journal of Autismand Developmental Disorders, 10, 203-213. Nevin, J.A. (1968). Differential reinforcement and stimulus control of not responding. Journal of the 
Experimental Analysis of Behavior, 11, 715-726. Pacitti, W.A. E Smith, N.F. (1977). A direct comparison of four methods for eliminating a response. Learning_ and Motivation. $8,229-237$.

Pliskoff, S.S. $\varepsilon$ Fetterman, J.G. (1981). Ondermatching and overmatching: The fixed-ratio changeover requirement. Journal of the Experimental Analysis of Behavior, 36. 21-27.

Plosgrove, I. \& Reith, H.J. (1983). Procedures for reducing children's inappropriate behavior in special education settings. Exceptional Education Quarterly. 3. $20-32$.

Ramsey, P. (1980). Exact type I error rates for robustness of student's $\underline{t}$ test with unequal variances. Journal of Eaucational statistics, 5, 337-349.

Rapport, M.D., Hurphy, A., E Bailey, J.S. (1982). Bitalin

vs. response cost in the control of hyperactive children: A vithin-subject comparison. Journal__of Applied Behavior Analysis, 15, 205-216. Reynolds, G.S. (1961). Behavioral contrast. Journal_of the Experimental Analysis of Behavion. 4. 57-71. Ravson, R.A. E Leitenberg, H. (1973). Reinforced alternative behavior during punishment and extinction with rats. Journal of Comparative and Physiological Psychology. 85, 593-600. Reese. E. (1978). Human operant behavior: Analysis and 
application (2nd ed.). Dubuque, Iowa: Nm. C. Brown Company -

Sidman, M. (1966). Aroidance Behavior. In M.K. Honig (Ed.) : operant behavior: Areas_of research and

application. New York: Appleton-Century-Crofts.

Skinner. B.F. (1938) - The Behavior of organisms- New

York: Appleton-Century-Crofts, Inc.

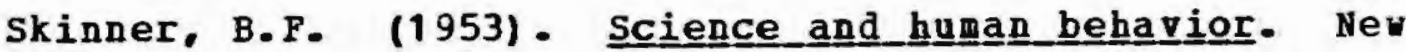

York: The Macmillan Company-

Skinner, B.F. (1976) - Farewe11, my lovely! Journal__of_the Experimental Analysis of Behavior. 25, 218.

Tarpley. H. E Schroeder, S. (1979). A comparison of DRO and DRI procedures in the treatment of self-injurious behavior. American_Journal of Mental Deficiency. 84 . $188-194$.

Jh1. C.N. E Garcia, E.E. (1969). Comparison of omission with extinction in rats. Journal of Comparative and Physiological psycholology, 69, 554-562.

Winer, B.J. (1971). Statistical principles in experimental

design (2nd ed.). Nev York: McGraw-Hill Book Company. Moods, T.C. (1983). DRO and DRI: A false dichotomy- The Psychologica 1 Recoro․․ 33. 59-66.

Zeiler. H.D. (1970). Other behavior: Conseguences of reinforcing not responding. The Journal of Psychology, 74. 149-155.

Zeiler, H. D. (1971) . Eliminating behavior with 
reinforcement. Journal of the Experimental analysis of Behavior, 16. 401-405.

Zeiler, H.D. (1976). Positive reinforcement and the

elimination of reinforced responses. Journal of the Experimental inalysis of Behavior, 26, 37-44. Zeiler, H.D. (1977). Elimination of reinforced behavior: Intermittent schedules of not-responding. Journal_of the Experimental Analysis of Behavior. 31, 23-32. Zeiler, H.D. (1979) - Reinforcing tbe absence of fixed-ratio performance. Journal of the ExperimentalAnalysis of Behavior. 31. 321-332. 
appendix $\mathbf{A}$

Hixed Design Analysis of Variance Summary Table For Total original Lever Responses for Each Group Across the Five sessions of the Training Phase

\begin{tabular}{|c|c|c|c|}
\hline Source & Sum of Squares & $\underline{d f}$ & Mean Square \\
\hline \multicolumn{4}{|l|}{ Betveen } \\
\hline Treatments & 134.212 .30 & 3 & $44,737.43$ \\
\hline Error & $1.292,146.66$ & 36 & 35.892 .96 \\
\hline \multicolumn{4}{|l|}{ Nithin } \\
\hline Sessions & 220.417 .83 & 4 & $55,104.46 \quad 38.66 * * *$ \\
\hline Sessions $\mathbf{x}$ & & & \\
\hline Treatments & $23,851.13$ & 12 & $1,987.59$ \\
\hline Error & $205,249.44$ & 144 & 1.425 .34 \\
\hline
\end{tabular}

*** $\mathrm{E}<.001$ 
Appendix $B$

Hixed Design Analysis of Variance Summary Table for Common log Transformed Tota 1 Responses During the Treatment phase

\begin{tabular}{|c|c|c|c|c|}
\hline Source & of Squares & df & Kean Square & e $\underline{E}$ \\
\hline \multicolumn{5}{|l|}{ Betreen } \\
\hline $\begin{array}{l}\text { Treatments } \\
\text { Error }\end{array}$ & $\begin{array}{r}5.17 \\
10.22\end{array}$ & $\begin{array}{r}3 \\
36\end{array}$ & $\begin{array}{l}1.72 \\
0.28\end{array}$ & $6.08 * *$ \\
\hline \multicolumn{5}{|l|}{ Hithin } \\
\hline $\begin{array}{l}\text { Sessions } \\
\text { Sessions } x\end{array}$ & 43.94 & 4 & 10.98 & $90.64 * * *$ \\
\hline $\begin{array}{l}\text { Treatments } \\
\text { Error }\end{array}$ & $\begin{array}{l}3.82 \\
17.45\end{array}$ & $\begin{array}{r}12 \\
144\end{array}$ & $\begin{array}{l}0.32 \\
0.12\end{array}$ & $2.63 * *$ \\
\hline
\end{tabular}

** p<.01

* * $p<001$ 
Appendix $\mathrm{C}$

Hixed Design Analysis of Variance Summary Table for the common log Transformed Total Besponses for Each Group Across the rive Sessions of the Extinction Phase

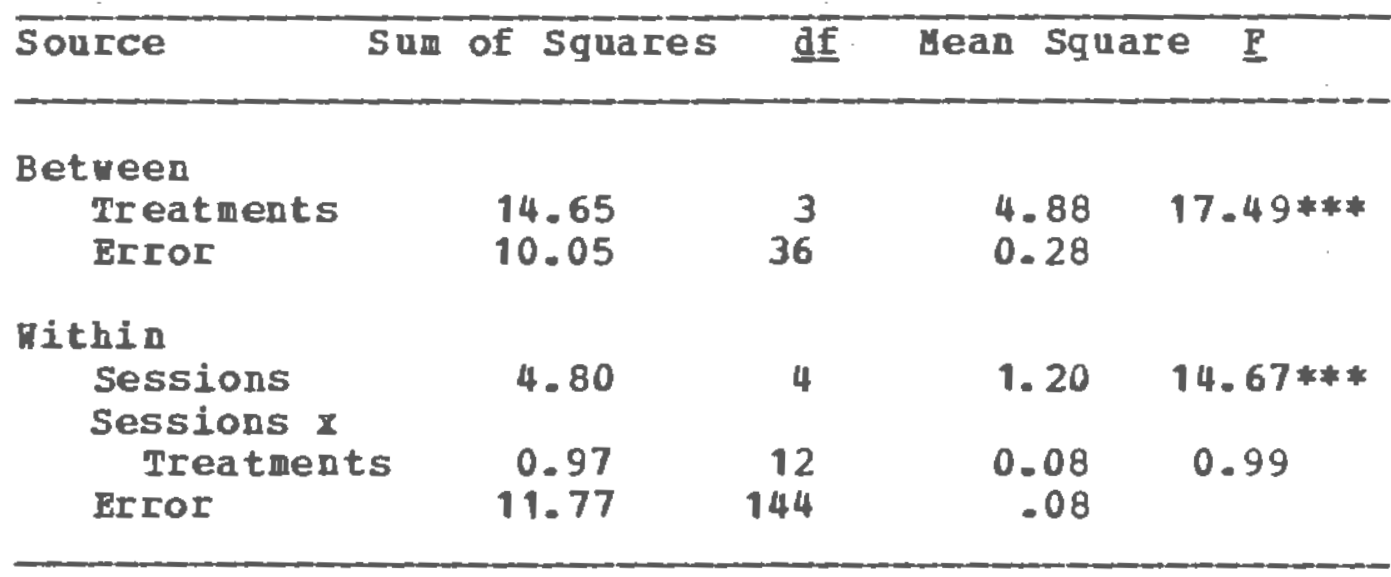

$* *$ pr.001 
Appendix D

Wixed Design Analysis of Vaciance Summary Table for Total oriqinal Lever Responses per binute for each Treatment Group Across the Fifteen binutes of the Reacquisition phase

\begin{tabular}{|c|c|c|c|c|}
\hline Source & of squares & df & Dean Square & $\underline{\mathbf{F}}$ \\
\hline \multicolumn{5}{|l|}{ Bet ween } \\
\hline Treatments & 5.84 & 3 & 1.95 & 1.25 \\
\hline Error & 55.98 & 36 & 1.56 & \\
\hline \multicolumn{5}{|l|}{ within } \\
\hline Time & 35.66 & 14 & 2.55 & $42.20 * * *$ \\
\hline Time $\mathbf{x}$ & & & & \\
\hline Treatments & 7.49 & 42 & 0.18 & $2.95 * * *$ \\
\hline Error & 30.42 & 504 & 0.06 & \\
\hline
\end{tabular}

*** $p<.001$ 
Appendix $E$

Analysis of Variance summary Table for Total

original Lever Responses dcross Both the

Treatment and Extinction phases

\begin{tabular}{lrrrrr}
\hline Source & Sum of squares & def & dean Square $\underline{F}$ \\
\hline $\begin{array}{l}\text { Betueen } \\
\text { Treatments }\end{array}$ & $100,547.30$ & 3 & 33.515 .77 & 0.88 \\
Error & 1.375 .048 .60 & 36 & 38.195 .79 & \\
\hline
\end{tabular}


Appendix $\mathbf{F}$

nixed Design Analysis of Variance Sumary Table

For log Trans formed Total A 1 ternate lever Responses_for Each Group Across the Five sessions of the Training Phase

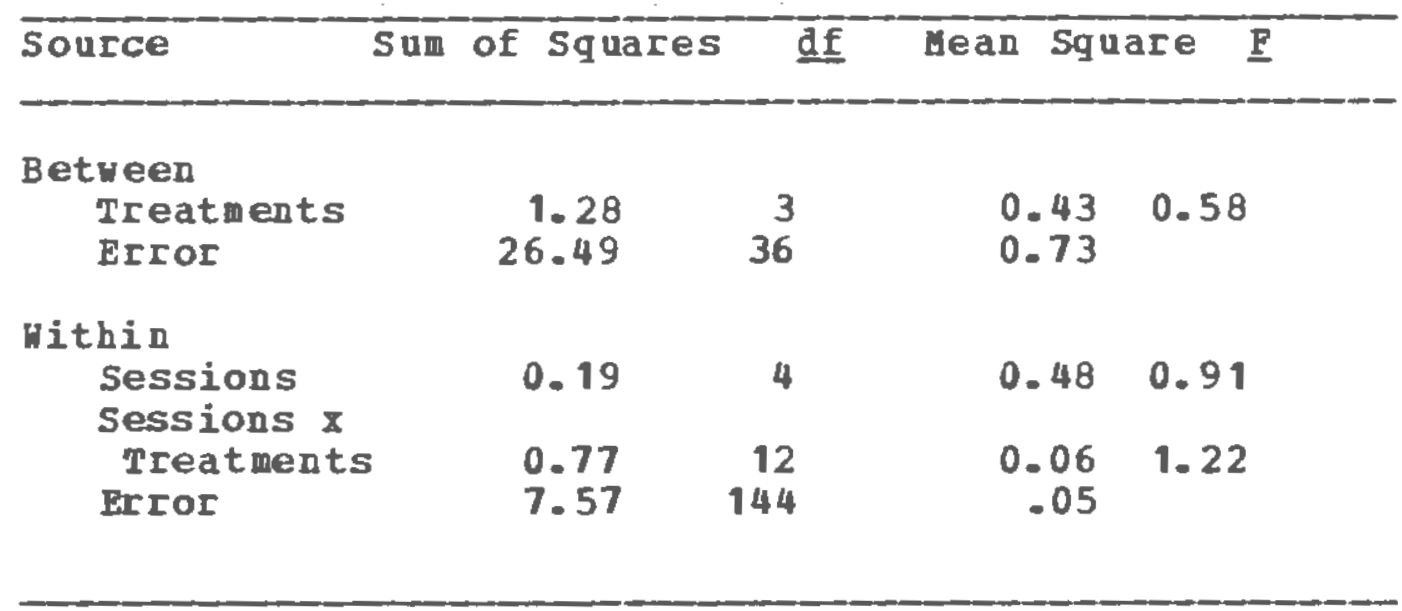


Appendix $G$

Gixed Desiqn Analysis of Variance summary Table For the Common log Transformed Alternate Lever Responses for Each Group Across the Five Sessions of the Treatment phase

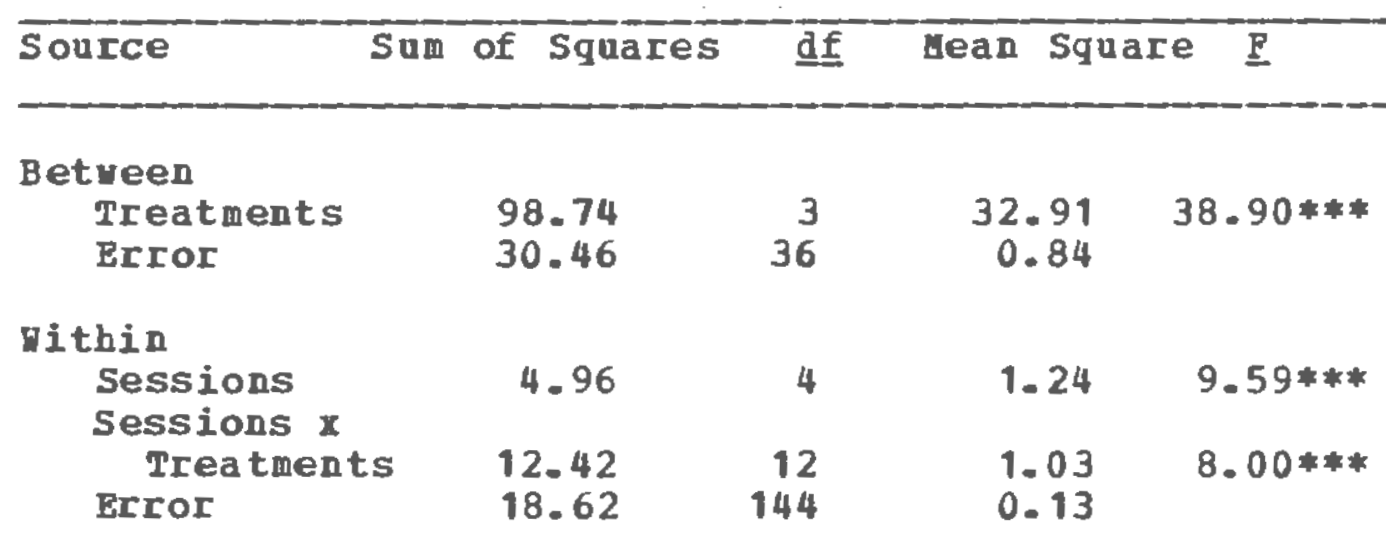

**4 $\mathrm{p}<.001$ 
Appendix $\mathrm{H}$

Mixed Design Analysis of Variance Summary Table for Common Log Transformed Total Alternate Lever Responses for each Group Across the Five_sessions of the Extinction phase

\begin{tabular}{|c|c|c|c|c|}
\hline Source & of squares & dff & Hean Square & $\underline{\underline{F}}$ \\
\hline \multicolumn{5}{|l|}{ Between } \\
\hline $\begin{array}{l}\text { Treatments } \\
\text { Error }\end{array}$ & $\begin{array}{l}62.16 \\
10.94\end{array}$ & $\begin{array}{r}3 \\
36\end{array}$ & $\begin{array}{r}20.72 \\
0.30\end{array}$ & $68.21 * * * n$ \\
\hline \multicolumn{5}{|l|}{ vithin } \\
\hline $\begin{array}{l}\text { Sessions } \\
\text { Sessions } x\end{array}$ & 8.39 & 4 & 2.10 & $24.11 * * *$ \\
\hline $\begin{array}{l}\text { Trea tments } \\
\text { Error }\end{array}$ & $\begin{array}{r}2.88 \\
12.52\end{array}$ & $\begin{array}{r}12 \\
144\end{array}$ & $\begin{array}{l}0.24 \\
0.09\end{array}$ & $2.76 * *$ \\
\hline
\end{tabular}

* p<.01

$* * * \mathrm{p}<001$ 
Appendix I

Hixed Design Analysis of Yariance_summar mar Table foror Log Transformed Total Alternate Iever Responses in the Reacquisisition $\underline{\text { ph }}$ hase

\begin{tabular}{|c|c|c|c|c|}
\hline Source & of squares & df & Eean Square & $\underline{\mathbf{F}}$ \\
\hline Betreen & & & & \\
\hline $\begin{array}{l}\text { Treatments } \\
\text { Error }\end{array}$ & $\begin{array}{r}3.19 \\
11.42\end{array}$ & $\begin{array}{r}3 \\
36\end{array}$ & $\begin{array}{l}1.06 \\
0.32\end{array}$ & $3.35 *$ \\
\hline Within & & & & \\
\hline $\begin{array}{l}\text { Time } \\
\text { Time } x\end{array}$ & 2.98 & 14 & 0.21 & $4.25 * *$ \\
\hline $\begin{array}{l}\text { Treatments } \\
\text { Error }\end{array}$ & $\begin{array}{r}5 \cdot 64 \\
25 \cdot 26\end{array}$ & $\begin{array}{r}42 \\
504\end{array}$ & $\begin{array}{l}0.13 \\
0.05\end{array}$ & $2.68 * *$ \\
\hline
\end{tabular}

* $\mathrm{p}<.05$

$* * \mathrm{p}<.01$ 
Appendix $\mathbf{J}$

Hixed Design Analysis of Variance Summary Table for Total Reinforcements per Group lcross the pire sessions of the Training phase

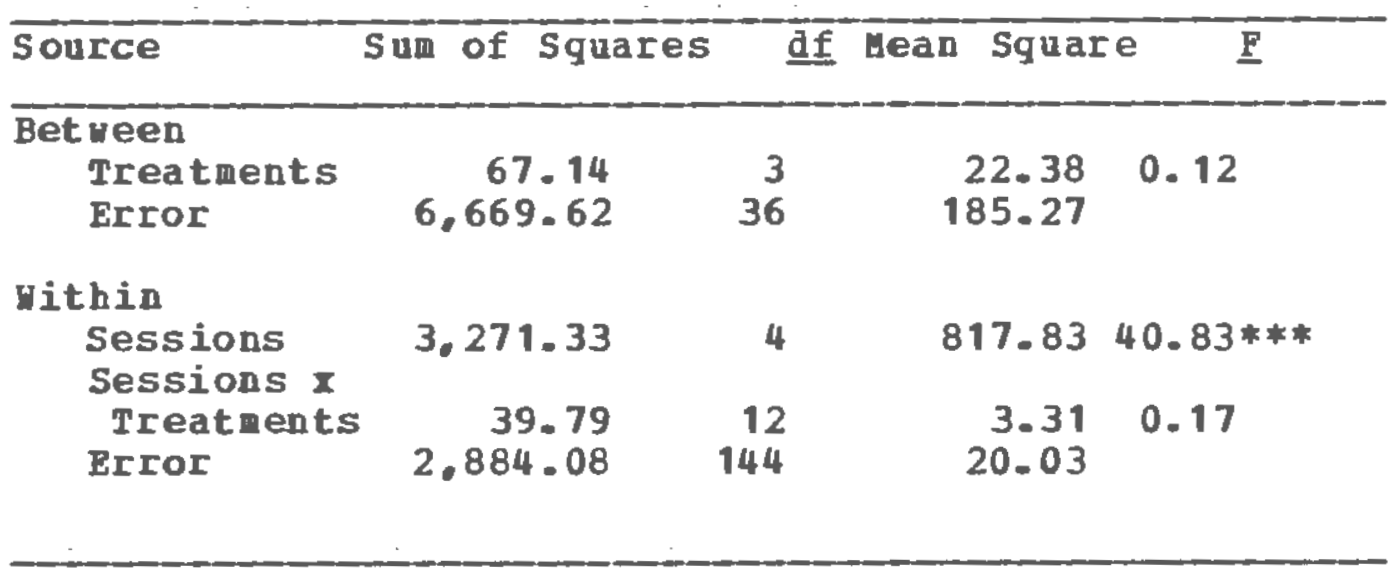

*** $\mathrm{P}<.001$ 


\section{Appendix $\mathrm{K}$}

Hixed Design Analysis of Variance Sumary Table For $\triangle$ rcsin Trans formed Total Reinforcements per Session for the Three Reinforcement-based Response Elimination Procedures Across the Five Sessions of the Treatment phase

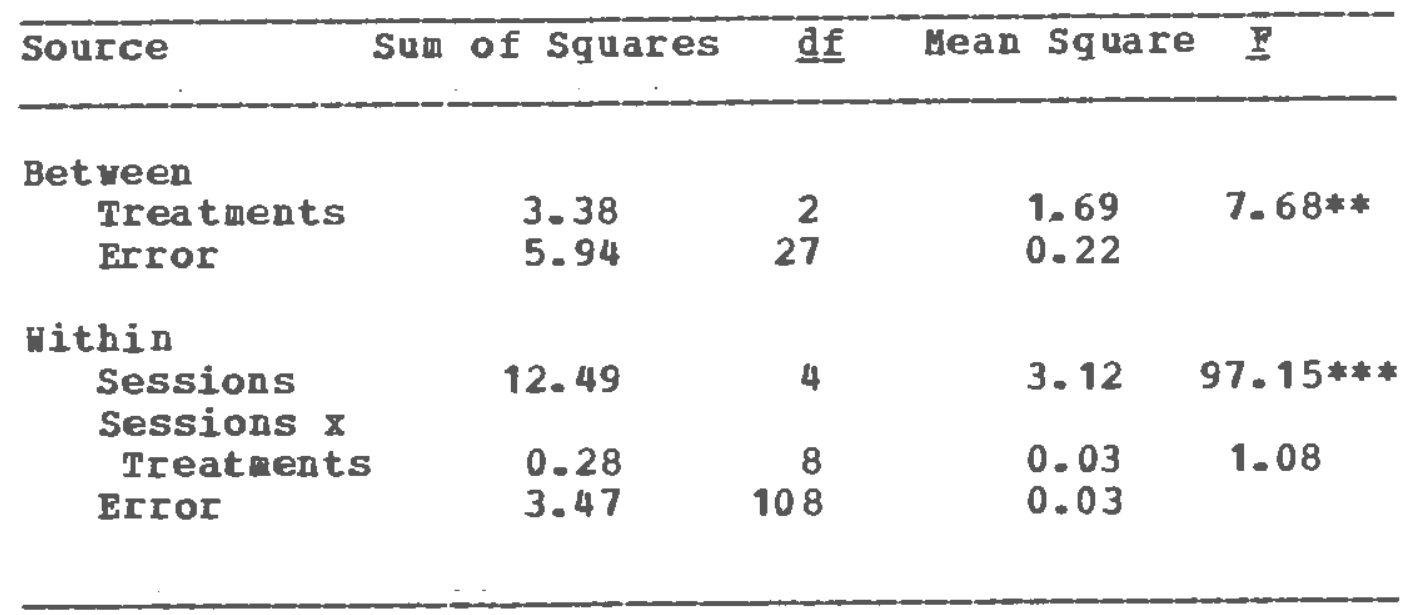

$*$ * $\mathrm{P}<.01$

$* *$ * $\mathrm{P}<.001$ 
Appendix I

Analyis of Yariance Summary Table for Total Arcsin Transformed Reinforcments per Ginute for Each Group Across the_Fifteen Hinutes of the Reacquisition Phase

\begin{tabular}{|c|c|c|c|c|}
\hline Source & of squares & $\underline{d \underline{f}}$ & Gean Squ & Ee \\
\hline \multicolumn{5}{|l|}{ Between } \\
\hline Treatments & 3.78 & 3 & 1.26 & 1.02 \\
\hline EIIOI & 44.41 & 36 & 1. 23 & \\
\hline \multicolumn{5}{|l|}{ Dithin } \\
\hline Time & 42.89 & 14 & 3.06 & $29.36 * *$ \\
\hline Time $x$ & & & & \\
\hline $\begin{array}{l}\text { Treatments } \\
\text { Error }\end{array}$ & $\begin{array}{l}8.53 \\
52.59\end{array}$ & $\begin{array}{r}42 \\
504\end{array}$ & $\begin{array}{l}0.20 \\
0.10\end{array}$ & $1.95 * * *$ \\
\hline
\end{tabular}

$* *$ p $<.001$ 